\title{
Functional lateralization of tool-sound and action-word processing in a bilingual brain
}

\begin{abstract}
BACKGROUND
The impact of bilingualism on lateralized brain functions such as praxis - the control of skilled actions - and language representations themselves, particularly in the auditory domain, is still largely unknown. Recent studies suggest that bilingualism affects both basic (fundamental frequency) sound and action-related speech processing. Whether it can impact non-verbal action sound processing is a question of debate.
\end{abstract}

PARTICIPANTS AND PROCEDURE

Here we examined twenty bilinguals using a dichotic listening paradigm, in which in addition to repeating the just heard action words, participants named - in Polish or English - one of two simultaneously presented tool sounds from attended ears. The results were compared with data from these same participants tested with reading the same words in a visual-half field paradigm.
RESULTS

In contrast to typical outcomes from monolinguals, the laterality indices of action-related sound processing (verbal and non-verbal) were not left lateralized but hemispherically balanced. Notably, despite similar organization of tool- and action-word sound processing, their auditory (balanced) and visual-language (left-lateralized) representations might be independent because there were no significant correlations between any of their laterality indices.

\section{CONCLUSIONS}

This indicates that bilingualism might involve reshuffling/ reorganization of typically lateralized brain functions and such plasticity will have consequences for second language learning strategies, as well as for neurorehabilitation.

\section{KEY WORDS}

bilingualism; tool sounds; action words; praxis; language learning

ORganization - 1: Faculty of Educational Studies, Adam Mickiewicz University, Poznan, Poland · 2: Action and Cognition Laboratory, Faculty of Psychology and Cognitive Science, Adam Mickiewicz University, Poznan, Poland .

3: Department of Neuroscience, West Virginia University, Morgantown, United States authors' Contributions - A: Study design - B: Data collection - C: Statistical analysis - D: Data interpretation .

E: Manuscript preparation · F: Literature search · G: Funds collection

CORRESPONDING AUthor - Prof. Michal Klichowski, Faculty of Educational Studies, Adam Mickiewicz University, 89 D Szamarzewskiego Str., 60-568 Poznan, Poland, e-mail: klich@amu.edu.pl 


\section{BACKGROUND}

Sounds are an important source of information for all mammals (Oertel, Cao, Ison, \& Allen, 2017). They are mostly used for locating other animals, especially when visual information is limited (Clarke \& Geiser, 2015). For people, sounds are not only a source of spatial information, but also of emotional experiences (Duffy, Waitt, \& Harada, 2016). Furthermore, humans categorize sounds in many different ways, for example separating verbal from non-verbal sounds (even infants can do this, Wild et al., 2017), separating action-related sounds from action-unrelated sounds, or distinguishing vocalization sounds produced by living organisms and man-made items, such as tools (Lewis, Brefczynski, Phinney, Janik, \& DeYoe, 2005, see also Crivelli, Rueda, \& Balconi, 2018; Schneider, Sundararajan, \& Mooney, 2018). Interestingly, when processing action-related sounds, including tool sounds, one can observe neural activity in motorrelevant areas of the human brain (Lewis, Phinney, Brefczynski-Lewis, \& DeYoe, 2006; Bourquin, Simonin, \& Clarke, 2013; Clarke \& Geiser, 2015), and in areas related to recognition and performance of actions (Rizzolatti et al., 1996; D’Ausilio et al., 2009), such as Broca's area (Binkofski \& Buccino, 2004; Corballis, 2010). Similar effects have also been observed in nonhuman primates. For example, when monkeys listen to sounds related to some type of action, the same neurons in area F5 (which is thought to be a homologue of human Broca's area) may fire as when they implement this very action (Kohler et al., 2002; Galati et al., 2008). This does not necessarily mean, however, that action-related sound processing and action performance rely on the same neural substrates; it merely indicates that there are some neural connections between areas involved in these functions in the primate brain (Helmich, Holle, Rein, \& Lausberg, 2015; de Borst, Valente, Jaaskelainen, \& Tikka, 2016).

Earlier studies by Lewis and collaborators (Lewis et al., 2005; Lewis et al., 2006) suggest that such links between tool sound representations and praxis representations can also be found in people. In right-handers who most often (in $96 \%$ of cases) have typically lateralized praxis skills (to the left hemisphere, e.g. Johnson-Frey, Newman-Norlund, \& Grafton, 2005; Lewis, 2006; Bidula \& Kroliczak, 2015; Corballis, 2017; see also Bornkessel-Schlesewsky, Schlesewsky, \& von Cramon, 2009; Przybylski \& Kroliczak, 2017; Styrkowiec, Nowik, \& Kroliczak, 2019), tool sound processing is also most often left lateralized (Lewis et al., 2005). On the other hand, in left-handers, where an atypical lateralization of praxis, as well as language, often occurs (in over $30 \%$ of cases either balanced or right hemisphere lateralization is found: Knecht et al., 2000; Johnson-Frey, 2004; Vingerhoets et al., 2012; see also Kroliczak, Piper, \& Frey, 2011; Vingerhoets et al., 2013; Somers et al., 2015; Joliot, Tzourio-Mazoyer,
\& Mazoyer, 2016; Bidula, Przybylski, Pawlak, \& Kroliczak, 2017), tool sound processing is also frequently atypically lateralized (more "towards" the right hemisphere, Lewis et al., 2006). The organization of many functions in the human brain, including praxis, may change, however, due to some experiences, especially those taking place at early stages of human development (Haberling, Corballis, \& Corballis, 2016; Lane et al., 2017; see also Michel, 2017). One of the experiences of this type is bilingualism (Costa \& SebastianGalles, 2014; Stein, Winkler, Kaiser, \& Dierks, 2014; Garcia-Penton, Perez Fernandez, Iturria-Medina, Gillon-Dowens, \& Carreiras, 2014; Kuhl et al., 2016). In the brains of bilingual people, changes are observed both at the subcortical level, in the context of brain morphology (Burgaleta, Sanjuan, Ventura-Campos, Sebastian-Galles, \& Avila, 2016), and at the level of the organization of functions (Grundy, Anderson, \& Bialystok, 2017). However, less is known about more specific neural consequences of bilingualism (Garcia-Penton et al., 2014). However, one might assume that bilingualism may result, for example, in a slightly different interhemispheric organization than in monolinguals (Hull \& Vaid, 2007; Felton et al., 2017), which could then be reflected, for example, in a more balanced representation of functions, including language (Burgaleta et al., 2016), and its relation to praxis skills (Fadiga, Craighero, Buccino, \& Rizzolatti, 2002; Pulvermuller \& Fadiga, 2010; Kroliczak et al., 2011; Haberling \& Corballis, 2015; Kroliczak, Piper, \& Frey, 2016; but cf. Poeppel, 2001). Moreover, a recent study (Skoe, Burakiewicz, Figueiredo, \& Hardin, 2017) suggests that in the human brain the organization of basic sound processing, which refers to the auditory neuroaxis (ability to process sounds that are not speech-specific, such as the fundamental frequency), is influenced by bilingual experience. The latter demonstration is of particular interest because there is also evidence that orally mimicked tool sounds (and animal vocalizations) in monolingual contexts (and/ or even monolingual individuals) engage left hemisphere structures (Lewis, Silberman, Donai, Frum, \& Brefczynski-Lewis, 2018).

In one of our previous studies (Klichowski \& Kroliczak, 2017), which utilized two paradigms aimed at studying functional lateralization (see Kimura, 2011) - dichotic listening (DL, see Hugdahl, 2012; HundGeorgiadis, Lex, Friederici, \& von Cramon, 2002) and visual-half field (VHF, see Hunter \& Brysbaert, 2008; Van der Haegen, Cai, Seurinck, \& Brysbaert, 2011; Verma \& Brysbaert, 2011; for evidence for compatibility of DL and VHF tests, see Oltedal \& Hugdahl, 2017) and stimuli in the form of words - we demonstrated that bilingualism (here: late bilingualism) could have also affected the processing of speechspecific sounds. (Note that we studied individuals who started second language learning as children, but typically well after the age of 6 ; in some ac-
Tool-sound processing in a bilingual brain 
Michal Klichowski, Agnieszka Nowik, Gregory Kroliczak, James W. Lewis counts early bilingualism takes place before the age of 6; see Reifegerste, Elin, \& Clahsen, 2019). The bilinguals who we examined revealed hemispherically balanced speech sound processing (whether uttered in their first or second language), demonstrating a rather typical productive language lateralization at the same time. Because in that study participants listened to action words, these outcomes suggest that bilinguals may not only have an atypical (more balanced) hemispheric organization of word-sound processing but also of other (e.g., non-verbal) actionrelated sounds, including tool sounds. (Note that in the human brain there is some evidence for a link between areas involved in processing the meaning of actions and representations of action-related sounds, Buccino et al., 2005; Fischer \& Zwaan, 2008; see also Bechtold et al., 2019).

In order to investigate whether or not bilinguals would also show atypical lateralization of non-verbal action-related sounds, we examined the majority of bilinguals from our previous study (Klichowski \& Kroliczak, 2017), utilizing the same paradigm as the one used for studying the lateralization of sounds (DL). However, instead of words, the participants listened to tool sounds, namely, exactly the same stimuli as the ones used in previous studies by Lewis et al. $(2005,2006)$, because in DL, verbal as well as non-verbal sounds can be effectively studied (Kimura, 2011). In short, we compared the lateralization of language processing and lateralization of actionrelated sound processing, in the form of action words and tool sounds. The comparison of these data sheds new light on the organization of sound processing in the bilingual brain.

\section{PARTICIPANTS AND PROCEDURE}

The experiment was conducted in the Action and Cognition Laboratory in the Institute of Psychology at Adam Mickiewicz University in Poznan, Poland. The study complied with guidelines of the local Ethics Committee for Research Involving Human Subjects and was carried out in accordance with the ethical principles of the 2013 World Medical Association Declaration of Helsinki (for details, see: https://www. wma.net/policies-post/wma-declaration-of-helsinkiethical-principles-for-medical-research-involvinghuman-subjects/).

The order of all tasks, performed either in English or Polish, and the majority of tests described here were counterbalanced across participants, except for tool sound processing, which was always presented last (but importantly, preceded equally often by the other tests and tasks; see below). Each test was taken on a different day (all the subjects visited the laboratory three times).

\section{PARTICIPANTS}

Twenty healthy volunteers (10 women, age range: $20-45$, mean $=27.75, S D=5.96)$ took part in this study. The experiment was conducted with the understanding and written consent of each participant. All subjects had normal hearing and normal or corrected-to-normal visual acuity. Nineteen individuals declared themselves as right-handed (with mean Laterality Quotient [LQ] $=94.58, S D=11.62$, and Laterality Score $[\mathrm{LS}]=61.84, S D=10.57)$, and one individual declared herself as typically left-handed (LQ $=-100$, and LS $=-70$ ), as confirmed by the results of the revised - shorter - version of the Edinburgh Handedness Inventory (Dragovic, 2004; cf. Veale, 2014). All participants were native speakers of Polish (L1) who also declared their late bilingualism (i.e., they started second language learning typically well after the age of 6; see Reifegerste et al., 2019) but high fluency in English (L2). Participants' fluency in L2 was established in three ways: (1) on the basis of their field of study - English Philology and/or Pedagogy in English at Adam Mickiewicz University in Poznan (Poland), and/or (2) the possession of language certificates (e.g., at least Certificate in Advanced English - CAE, typically higher; as in the study by Krefta, Michalowski, Kowalczyk, \& Kroliczak, 2015), and/or (3) the requirement of fluent command of English for performing a job in international companies.

\section{STIMULI AND PROCEDURE}

Visual half-field (VHF) tests. The stimuli were the following: 20 Polish action words, 20 English action words (see Klichowski \& Kroliczak, 2017). The action words were in their infinitive forms in Polish, and typically in non-finite, gerund forms in English. The rationale was to minimize the difference in length between Polish and English action words. Note that Polish verbs are typically much longer than the corresponding English verbs. For the list of stimuli used in our VHF test, see Appendix A.

Participants were seated in front of a monitor at a viewing distance of $\sim 57 \mathrm{~cm}$ (as in Klichowski \& Kroliczak, 2017). Each trial started with a central fixation cross of a duration of 1000 milliseconds (ms). Next, two stimuli were presented in the left (LVF) and right visual field (RVF) with a central arrow pointing to the left or right. The role of the arrow was to indicate the target stimulus. The participants were instructed to read out loud the target stimulus, and to ignore the non-target stimulus. Each stimulus was presented as a target or non-target. All stimuli were displayed in Times New Roman font, with 50 points size - subtending 3.5 to 8.5 degrees of visual angle for the shortest and longest words, respectively, and $2 \mathrm{deg}$. for their heights, and were shown in black color on a white background. 
After $217 \mathrm{~ms}^{1}$, both stimuli were masked with strings of hash marks (the length of the presented string was always equal to the length of the masked stimulus). Then, only a central arrow pointing to the place where the target was shown remained on the screen and stayed there until a vocal response was registered. A blank screen of a variable (1250, 1500, or $1750 \mathrm{~ms})$ duration was introduced between successive trials. Trial structure and timing are depicted in Figure 1.

The VHF test consisted of two pseudo-randomly presented blocks of trials, which for convenience will be called first and second. In the first block, action words were written in Polish and the participant was instructed to read them in this language, while in the second block, action words were written in English and the participant was instructed to read them in that language. At the beginning of a given block, participants were informed of its type. The language of instructions always corresponded to the language used in a given block. In total, each block consisted of forty trials. Note that before the actual experiment, a training session was administered. Stimuli used during the training session did not appear in the subsequent experiment.

Dichotic listening (DL) tests. The action words from VHF tests ( ${ }^{*}$.wav files; recorded by an academic teacher of English pronunciation; see Klichowski \& Kroliczak, 2017) and 20 unique tool sounds were used. The tool sounds (also *.wav files) were obtained from previous studies (Lewis et al., 2005, 2006) by selecting the most common twenty. For the list of stimuli used in DL tests,

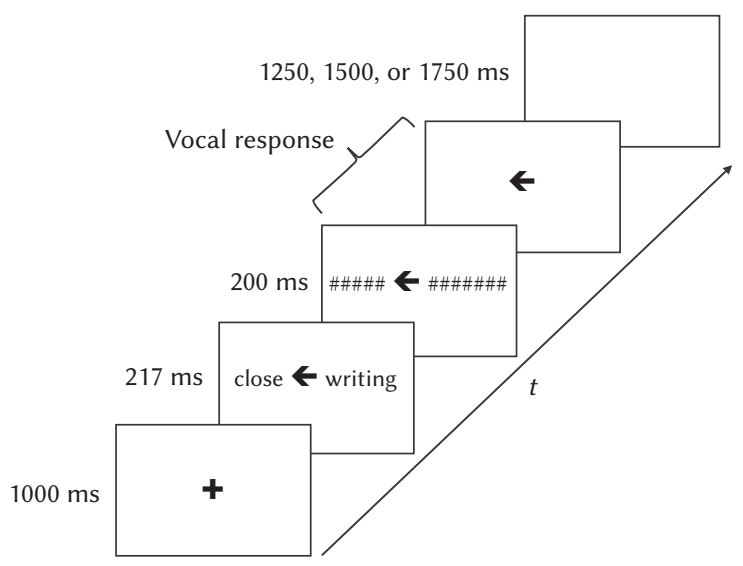

Figure 1. Trial structure and timing in visual halffield tests. After a fixation point was presented on a blank screen for 1000 ms, two stimuli (the target stimulus and the non-target stimulus) were shown bilaterally for $217 \mathrm{~ms}$, with a central arrow pointing to the location of the target. 200-ms masks then covered the stimuli. After the onset of a participant's vocal response, a blank screen of variable duration (1250, 1500, or $1750 \mathrm{~ms}$ ) was introduced and preceded the next trial. see Appendix B. While only seven items from the action word and tool sound lists overlapped (as not all actions are associated with sounds, or can be easily identified by sounds), all of them are commonly known.

As before, participants were seated in front of a monitor at a viewing distance of $\sim 57 \mathrm{~cm}$. Each trial started with a central fixation cross of a duration of $1000 \mathrm{~ms}$. Next, two stimuli with synchronized onsets were presented separately to the left (LE) and right ear (RE), via an 'HS-702' PC-Headset speaker, together with a central arrow displayed on the computer monitor and pointing either to the left or right. The role of the arrow was to indicate the target stimulus. The participants were instructed to repeat aloud the target action words, or to name the target tool sounds, and to ignore the non-target stimuli. Each stimulus was presented as a target and as a non-target, in the left and right ear. A blank screen with a central arrow pointing to one of the sides was displayed until a vocal response was registered. A blank screen of variable (1250, 1500, or $1750 \mathrm{~ms}$ ) duration was introduced between successive trials. The trial structure is depicted in Figure 2.

Before the actual test, a training (action word processing) or learning (tool sound processing) session was administered. A training session consisted of two blocks similar to the actual test. During the learning session, participants listened to tool sounds and learned their names (action names). The training/learning session was repeated twice. Notably, before the training/learning session the participants - listening to various sounds - were asked to set the

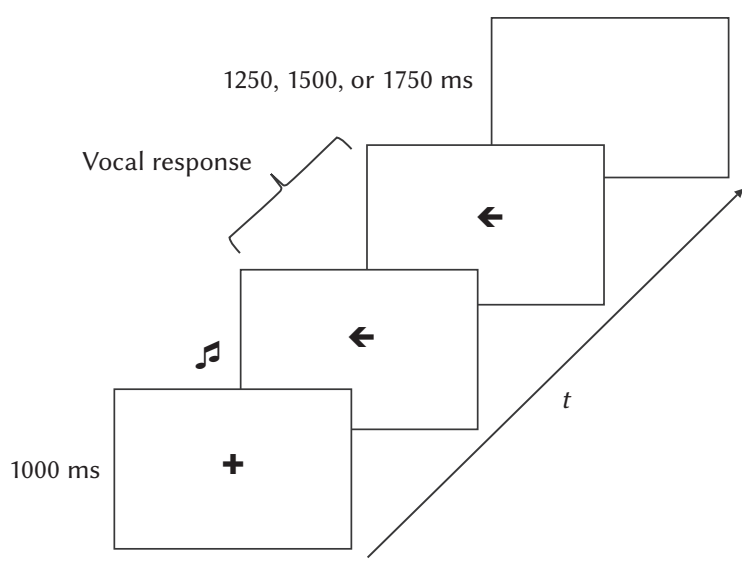

Figure 2. Trial structure and timing in dichotic listening test. After a fixation point was presented on a blank screen for $1000 \mathrm{~ms}$, two stimuli (the target stimulus and the non-target stimulus) were presented in the left and right ear (headset speaker), with a central arrow pointing to the location of the target. After the onset of a participant's vocal response, a blank screen of variable duration (1250, 1500 , or $1750 \mathrm{~ms}$ ) was introduced and preceded the next trial.
Tool-sound processing in a bilingual brain 
Michal Klichowski, Agnieszka Nowik, Gregory Kroliczak, James W. Lewis volume for each ear (each headset speaker), so that they had a subjective feeling of equal stimulus volume in both ears. The language of the training/learning session and instruction always corresponded to the language used in a given block.

Similar to the VHF test, the DL tests consisted of two pseudo-randomly presented blocks of trials, which again for convenience will be referred to as first and second. For action word processing in the first block the participant was instructed to repeat Polish action words, while in the second block, he/she was instructed to repeat English action words. For tool sound processing, in the first block the participant was instructed to name tool sounds in Polish, and in the second one, to name tool sounds in English. At the beginning of a given block, the participants were informed of its type. In total, each block consisted of forty trials.

All experiments (i.e., both VHF and DL tests) were implemented in SuperLab 4.5.4 for Mac by Cedrus (http://www.superlab.com/). The visual stimuli or cues were presented on a 21.5-inch Apple iMac monitor. Response times (RTs), as measured by the onset of the vocal reaction, were detected by the SV-1 Smart Voice Key (http://www.cedrus.com/sv1/). As only vocal reaction times are acquired by the voice key, the experimenter constantly monitored response accuracy (ACC).

\section{DATA ANALYSES}

To investigate the lateralization of stimulus processing, laterality indices (LIs) were obtained using the following formulae, separately for accuracy ( $\mathrm{LI}_{\mathrm{ACC}}$ ) and response times $\left(\mathrm{LI}_{\mathrm{RT}}\right)$ :

$$
\begin{aligned}
& \mathrm{LI}_{\mathrm{ACC}}=\left(\left[\mathrm{R}_{\mathrm{acc}}-\mathrm{L}_{\mathrm{acc}}\right] /\left[\mathrm{R}_{\mathrm{acc}}+\mathrm{L}_{\mathrm{acc}}\right]\right)^{*} 100 \\
& \mathrm{LI}_{\mathrm{RT}}=\left(\left[\mathrm{L}_{\mathrm{rt}}-\mathrm{R}_{\mathrm{rt}}\right] /\left[\mathrm{L}_{\mathrm{rt}}+\mathrm{R}_{\mathrm{rt}}\right]\right) * 100
\end{aligned}
$$

For $\mathrm{LI}_{\mathrm{ACC}}$ calculations, $\mathrm{R}$ and $\mathrm{L}$ represent response accuracy $(\%)$ for stimuli presented in the RVF and LVF (VHF), or in the right and left ear, RE and LE, respectively (in DL). For $\mathrm{LI}_{\mathrm{RT}}$ calculations, $\mathrm{L}$ and $\mathrm{R}$ represent mean response times (ms) in correct trials with stimuli presented in the LVF and RVF (VHF), or in the LE and RE (DL).

Positive values of $\mathrm{LI}_{\mathrm{ACC}}$ and/or $\mathrm{LI}_{\mathrm{RT}}$ indicate right visual field/ear advantage, thus left hemisphere dominance. A reversed effect (negative values) indicates left visual field/ear advantage, thus right hemisphere dominance. Finally, significant differences between LIs for different stimuli or languages might indicate that these stimuli/languages are differently lateralized in the brain. Consequently, correlational analyses of LIs for L1 and L2 or for stimuli from VHF and DL allowed us to examine whether or not representations of $\mathrm{L} 1$ are truly related to the representations of L2, and whether or not there are links between the representations of action-related sounds and the representations of languages.
For each test, two separate ( 1 for response accuracies and 1 for response times) $2 \times 2$ repeated-measures analyses of variance (rm-ANOVA) were conducted, with the following within-subjects factors: language (L1, L2) and target location (RVF, LVF or RE, LE). To compare differences between LIs, $t$-tests for dependent samples were also used. When LIs from different tests were contrasted, supplemental $3 \times 2$ rm-ANOVAs were run with test type (VHF: action word processing, DL: action word processing, DL: tool sound processing) and language (L1, L2) as within-subjects factors. Where necessary, the required post-hoc tests of simple main effects were Bonferroni corrected. Finally, to investigate whether or not representations of L1 and L2, or representations of language and action-related sounds (or each other), share any common organizational features, we performed correlational analyses of LIs using Pearson correlations method $(r)$.

The adopted level of significance was $\alpha=.05$. For reaction times accompanying correctly recognized stimuli, outliers greater than two standard deviations above or below the mean (calculated for each condition) were removed due to the possibility of an equipment malfunction and/or participants guessing the answer. All statistical analyses were carried out using IBM SPSS Statistics 24.0.

\section{RESULTS}

\section{VISUALLY PRESENTED ACTION WORD PROCESSING}

Figure 3A shows that for ACC there was no main effect of language $(F(1,19)=0.90)$. However, we observed a main effect of target location $(F(1,19)=66.27$, $p<.001)$, such that ACC was significantly better for action words presented in RVF (72.2\%), as compared to LVF $(44.0 \%)$ (difference between means $=28.2 \%$, $S E=3.5 \%, B f-p<.001)$. Although we observed language by target location interaction $(F(1,19)=7.55$, $p<.05)$, this effect, as Figure 3C shows, occurs both for L1 (difference between means $=33.5 \%, S E=4.3 \%$, $B f-p<.001$ ) and L2 (difference between means $=23.0 \%$, $S E=3.6 \%, B f-p<.001)$, with the latter difference being slightly smaller.

For RT the main effect of language was significant $(F(1,19)=21.50, p<.001)$, and it was such that participants read action words faster in L1 (mean $=1061 \mathrm{~ms})$, as compared to L2 (mean $=1179 \mathrm{~ms}$ ) (difference between means $=118 \mathrm{~ms}, S E=25 \mathrm{~ms}, B f-p<.001)$. This effect is depicted in Figure 3B. We also observed a main effect of target location $(F(1,19)=15.08, p=.001)$, such that participants read action words presented in RVF faster (mean = $1067 \mathrm{~ms}$ ), as compared to LVF $($ mean $=1173 \mathrm{~ms})$ (difference between means $=106 \mathrm{~ms}$, $S E=27 \mathrm{~ms}, B f-p<.01)$. While the language by target location interaction was not significant $(F(1,19)=1.59$, 
$p=.077$ ), a priori comparisons revealed, as Figure 3D shows, that responses towards action words presented in RVF both for L1 were substantially faster (difference between means $=124 \mathrm{~ms}, S E=22 \mathrm{~ms}, B f-p<.001)$ than those for L2 (difference between means $=87 \mathrm{~ms}$, $S E=38 \mathrm{~ms}, B f-p<.05)$, as compared to LVF.

Finally, there were no significant differences between lateralization of action word processing (or more precisely, between action word LIs) for L1 and L2.
Figure 4A-B shows that this effect (a right visual-field/ left hemispheric domination) occurs neither for ACCbased LIs (difference between means $=6.48, S E=4.01$, $t(19)=1.62, p>.05)$ nor RT-based LIs (difference between means $=2.12, S E=1.13, t(19)=1.88, p>.05)$. However, we found strong significant correlations between individuals' L1 and L2 LIs, for both ACC-based LIs $(r=.56, p=.010)$ and RT-based LIs $(r=.60, p<.01)$. These effects are shown in Figure 4C-D.

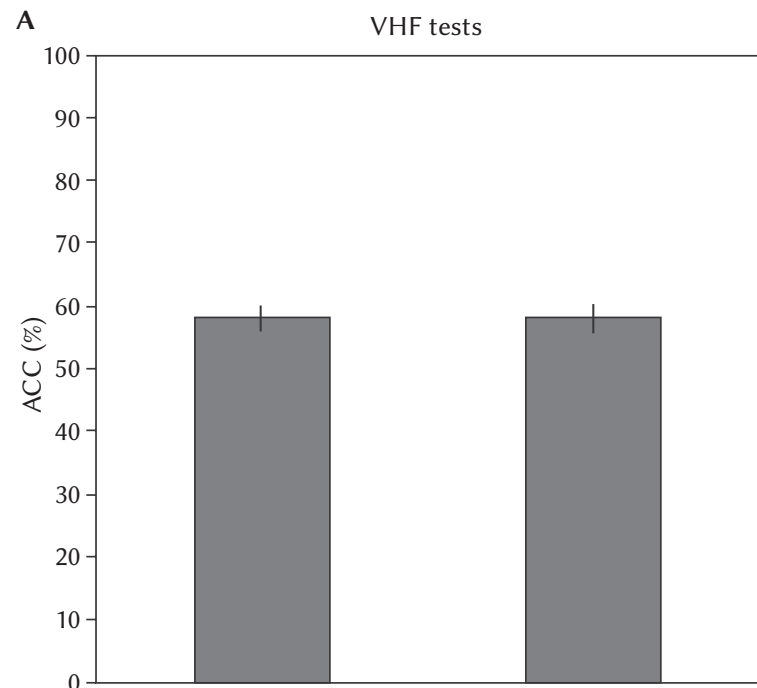

L1

C

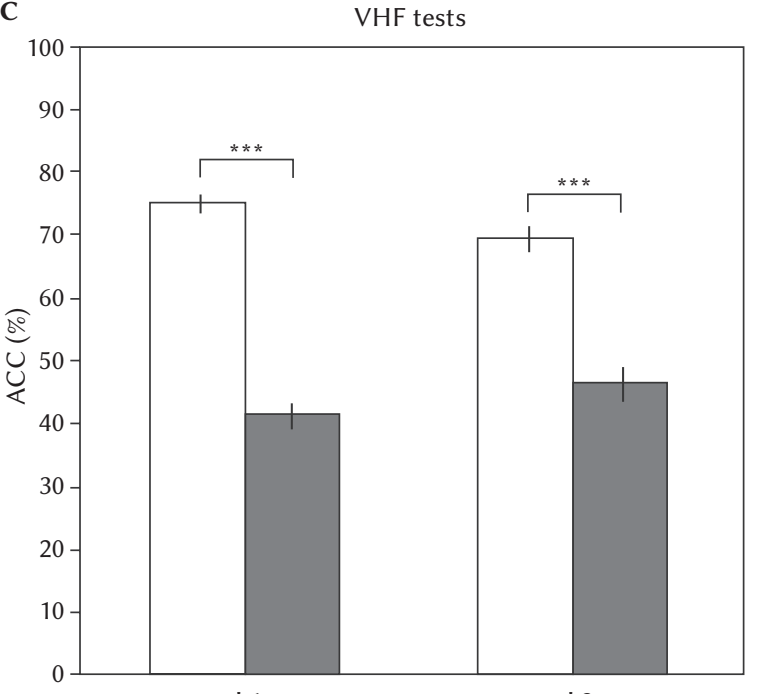

B

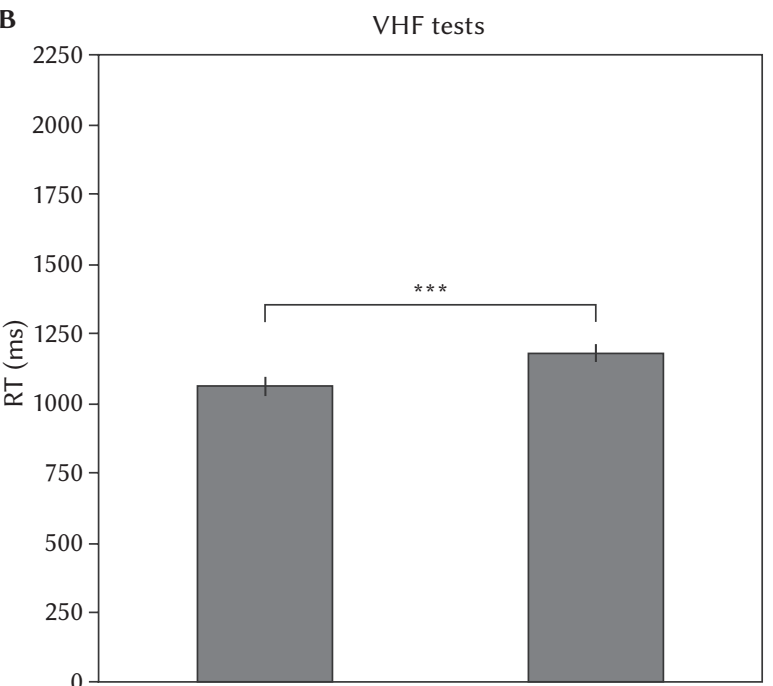

L1

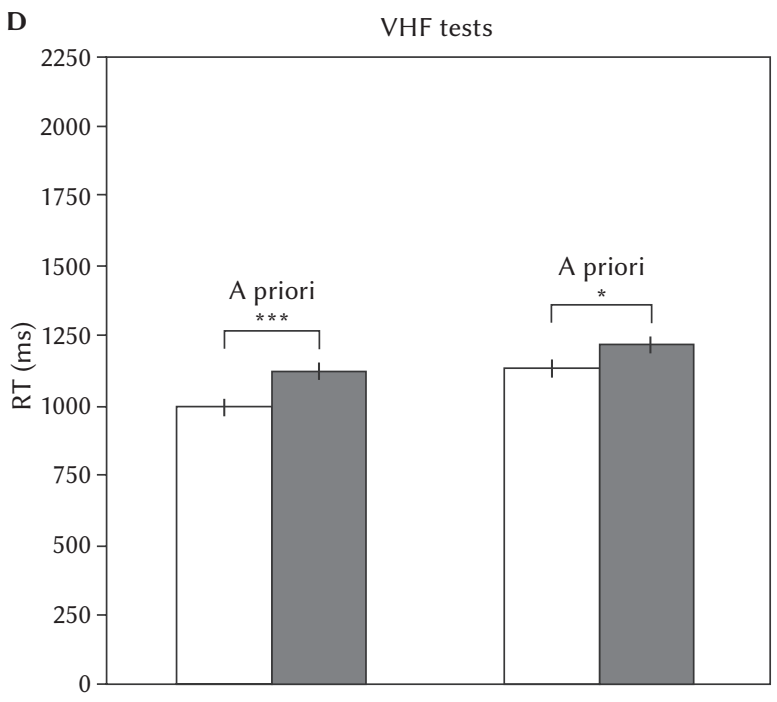

D

L1
Tool-sound processing in a bilingual brain

$\square$ RVF $\square$ LVF

Figure 3. Visual half-field (VHF) processing of action words. (A) Differences between accuracy (ACC) for action word reading in the first language (Polish, L1) and second language (English, L2): No significant effects. (B) Differences between response times (RTs) for correctly read action words in L1 and L2: RTs were significantly faster for L1. (C) Differences between ACC for reading action words presented in right visual field (RVF) and left visual field (LVF): ACC was significantly better for RVF both in L1 and in L2. (D) Differences between RTs for correctly read action words presented in RVF and LVF: RTs were significantly faster for RVF (as compared to LVF) both in L1 and in L2, with the difference for the former tending to be substantially greater. Only significant results are indicated here. Asterisks indicate significant $p$-values: ${ }^{*} p<.05$, ${ }^{* * *} p<.001$. Error bars depict standard errors of the means. 


\section{AUDITORILY PRESENTED ACTION WORD PROCESSING}

Figure 5A shows that for ACC there was a main effect of language $(F(1,19)=8.37, p<.01)$, such that ACC was significantly higher for action words repeated in L1 (83.1\%), as compared to L2 $(75.0 \%)$ (difference between means $=8.1 \%, S E=2.8 \%, B f-p<.01)$. However, as Figure 5C shows, there was no main effect of target location $(F(1,19)=0.45, p>.05)$ and the language by target location interaction was not significant, either $(F(1,19)=0.48, p>.05)$. Figure 5B-D shows that for RT there were no significant effects (all $p>.05$ ).
Michal Klichowski, Agnieszka Nowik, Gregory Kroliczak, James W. Lewis
A

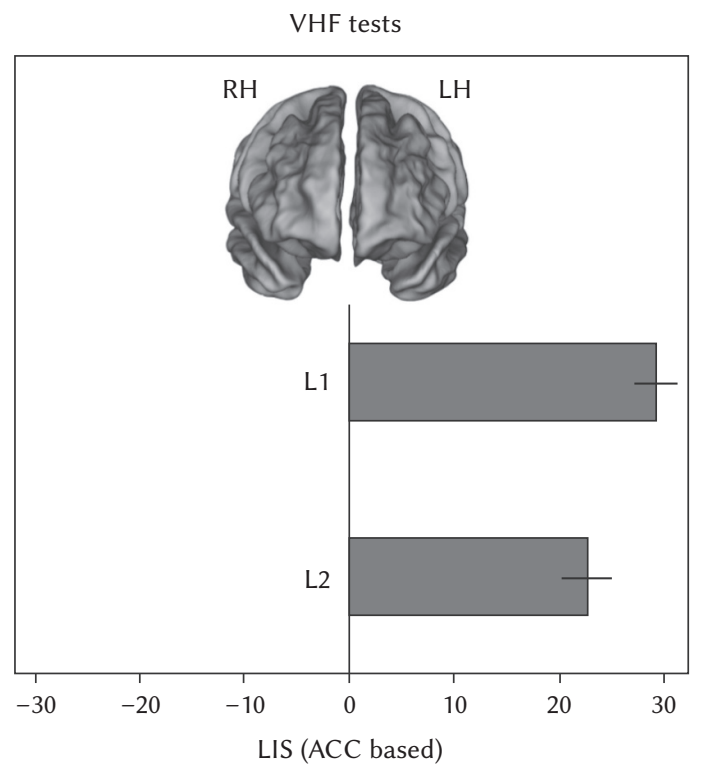

C

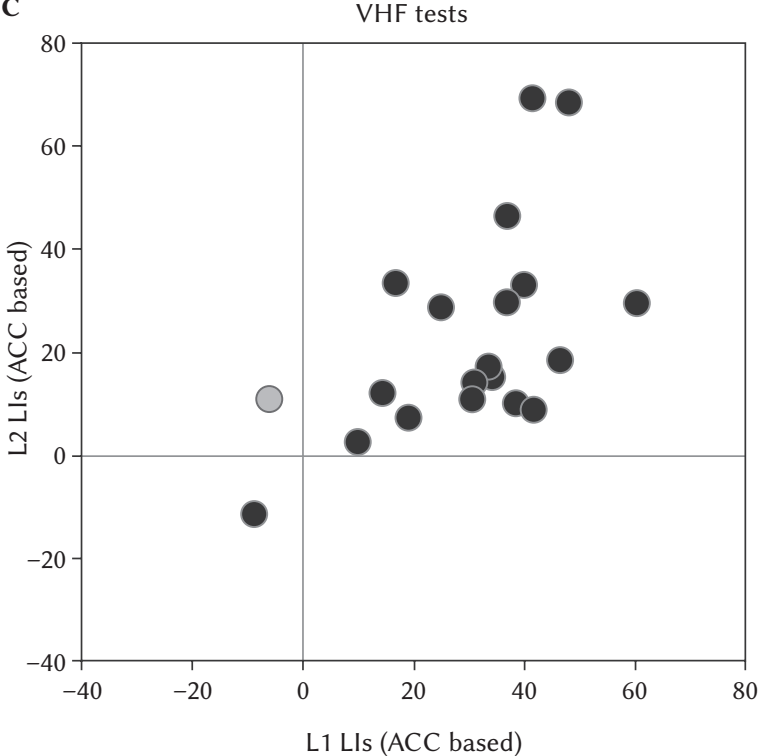

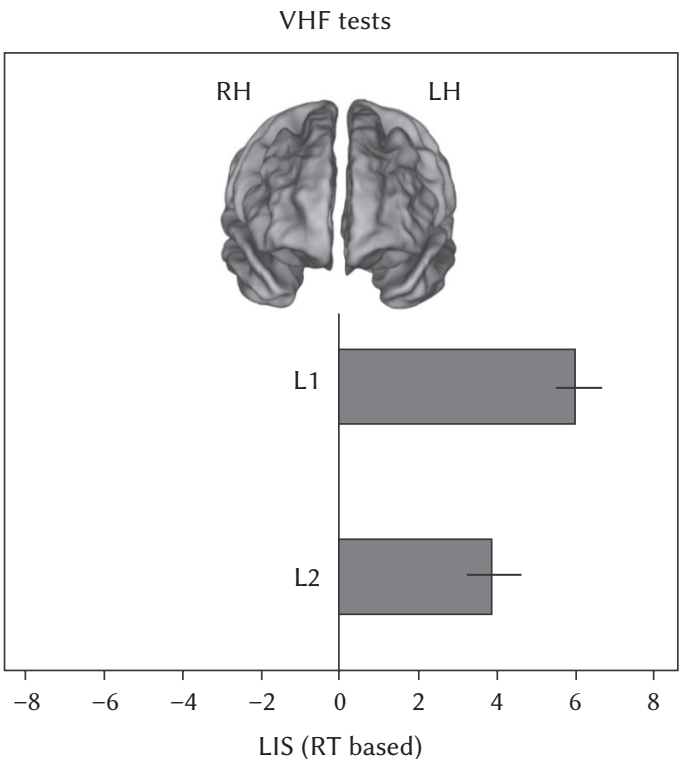

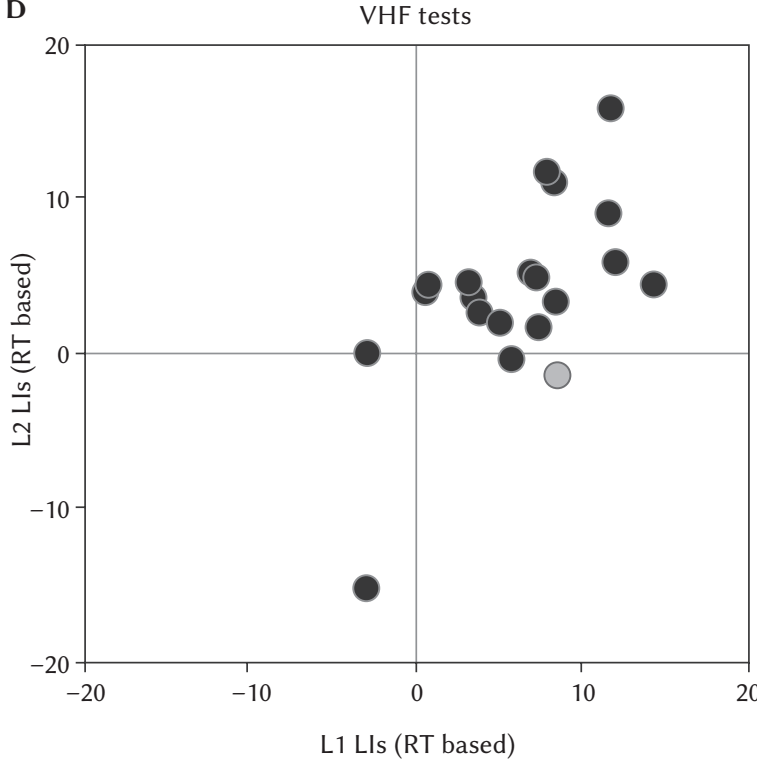

Figure 4. Hemispheric organization (laterality indices, LIs) of processing for visually presented action words in the first language (Polish, L1) and second language (English, L2). (A) Accuracy (ACC)-based LIs: No significant differences between lateralization of action word processing in L1 and L2. (B) Response-time (RT)-based LIs: No significant differences between lateralization of action word processing in L1 and L2. (C) Individual ACC-based LIs: There were significant correlations between lateralization of action word processing in L1 and L2. (D) Individual RT-based LIs: There were significant correlations between lateralization of action word processing in L1 and L2. LH - left hemisphere, RH - right hemisphere; VHF - visual halffield; black dots - right-handed participants; gray dot - left-handed participant. Error bars depict standard errors of the means. 
There were no significant differences between lateralization of action word processing (or more precisely, between action word LIs) for L1 and L2, either. Figure 6A-B shows that this effect (no ear/ hemispheric dominance) occurs both for ACC-based LIs (difference between means $=2.25, S E=3.24$, $t(19)=-0.69, p>.05)$ and RT-based LIs (difference between means $=2.41, S E=1.39, t(19)=1.74, p>.05)$. Nevertheless, as Figure 6C-D shows, there were no significant correlations between individuals' L1 and
L2 LIs, for both ACC-based LIs $(r=.27, p=.252)$ and RT-based LIs $(r=.27, p=.253)$.

\section{TOOL SOUND PROCESSING}

Figure 7A shows that for ACC there was a main effect of language $(F(1,19)=6.47, p<.05)$, such that participants were better in processing tool sounds in L1 (59.7\%), as compared to L2 (50.4\%) (difference

Tool-sound processing in a bilingual brain

A

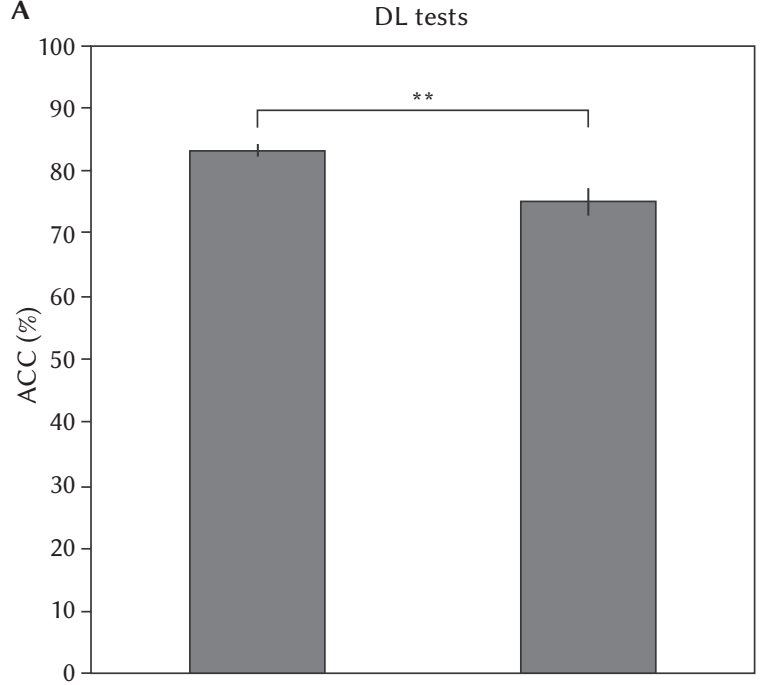

L1

C

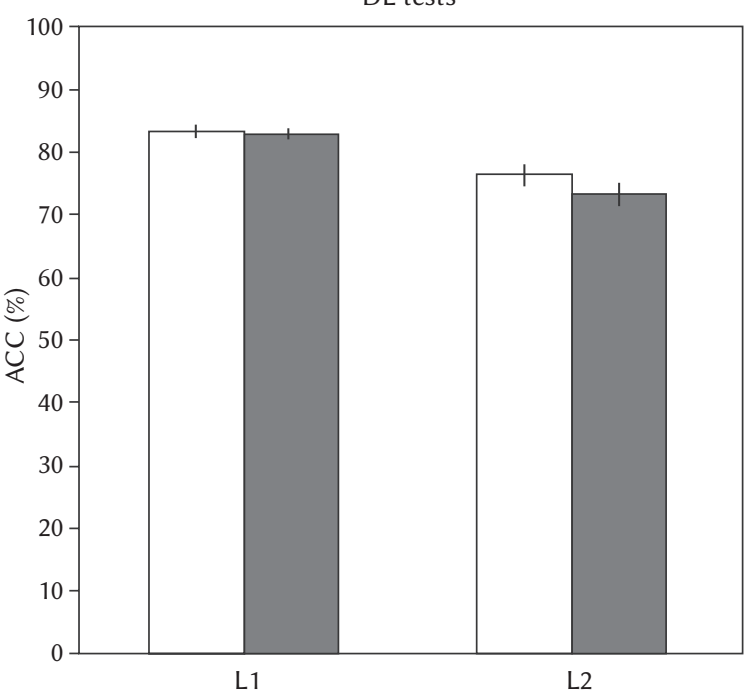

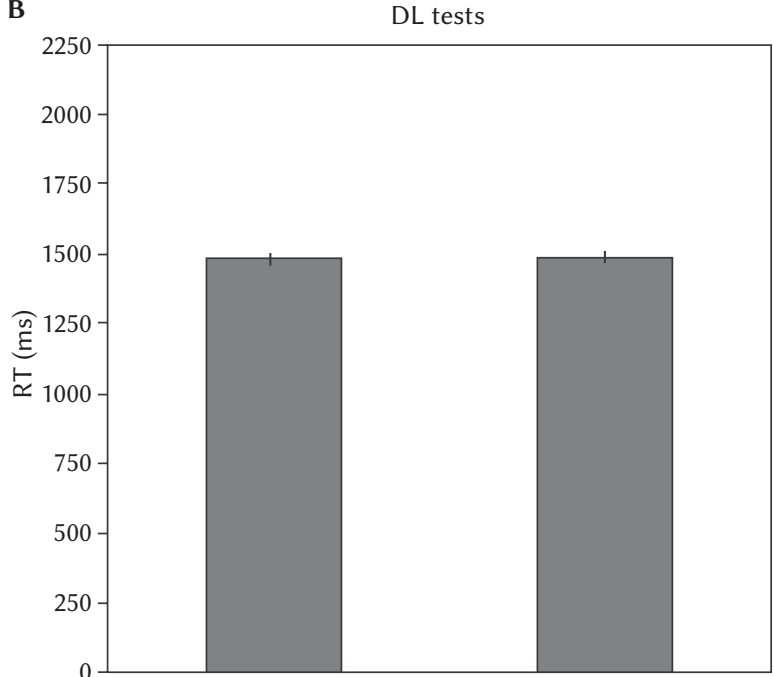

L1

D

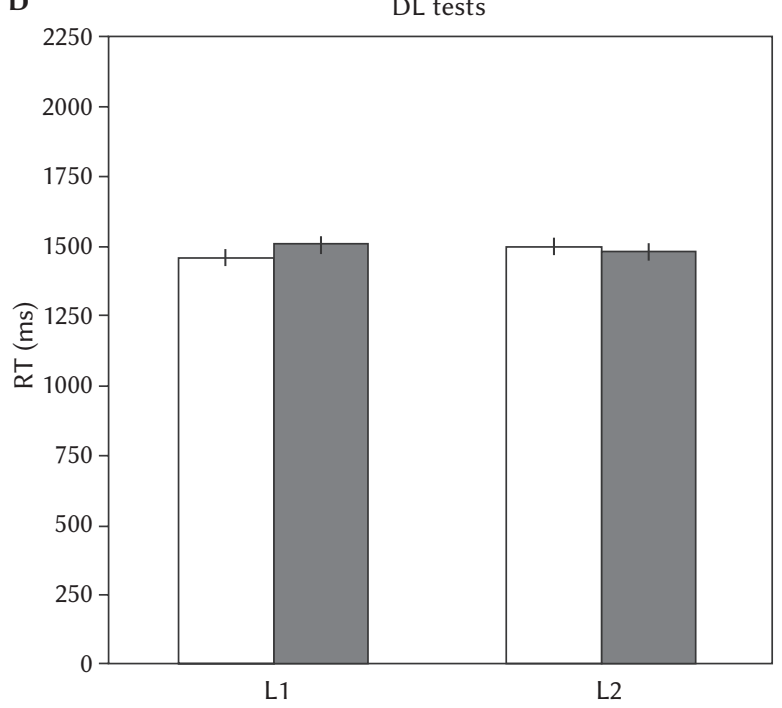

$\square$ RE

LE

Figure 5. Dichotic listening (DL) involving action words. (A) Differences between accuracy (ACC) for action word processing in the first language (Polish, L1) and second language (English, L2): ACC was significantly higher for L1. (B) Differences between response times (RTs) for correctly repeated action words in L1 and L2: No significant effects. (C) Differences between ACC for action words presented in right ear (RE) and in left ear (LE): No significant effects. (D) Differences between RTs for correctly repeated action words presented in RE and LE: No significant effects. Asterisks indicate significant $p$-values: ${ }^{* *} p<.01$. Error bars depict standard errors of the means. 
between means $=9.4 \%, S E=3.7 \%, B f-p<.05) . \mathrm{Nev}^{-}$ ertheless, there was no main effect of target location $(F(1,19)=0.33, p>.05)$. Figure $7 \mathrm{C}$ shows that the language by target location interaction was not significant either $(F(1,19)=4.06, p>.05)$.

A similar pattern of results was observed for RTs. As Figure 7B shows, we found a main effect of lan- guage $(F(1,19)=5.72, p<.05)$, such that participants named tool sounds faster in L1 (2027 ms), as compared to L2 $(2181 \mathrm{~ms})$ (difference between means $=154 \mathrm{~ms}$, $S E=64 \mathrm{~ms}, B f-p<.05)$. There was no main effect of target location $(F(1,19)=0.07, p>.05)$, and, as Figure 7D shows, the language by target location interaction was not significant, either $(F(1,19)=0.98, p>.05)$.
Michal Klichowski, Agnieszka Nowik, Gregory Kroliczak, James W. Lewis
A

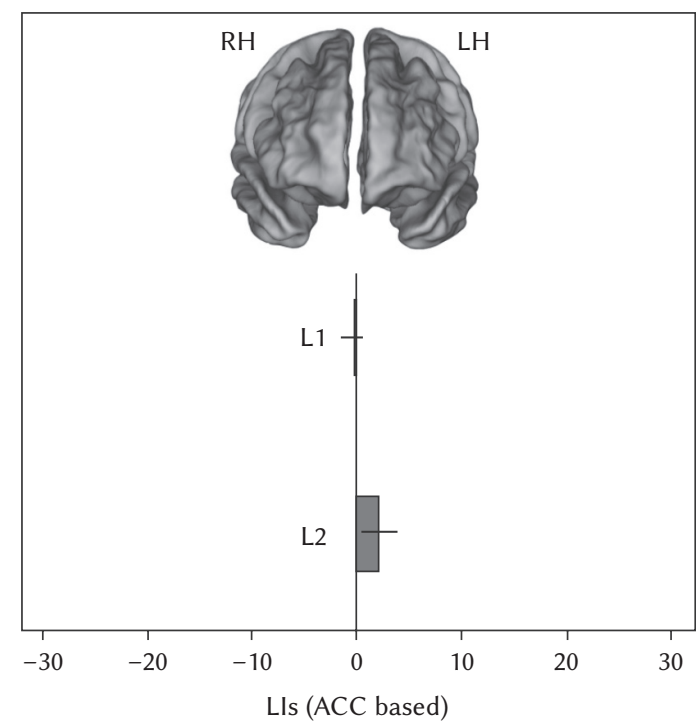

C

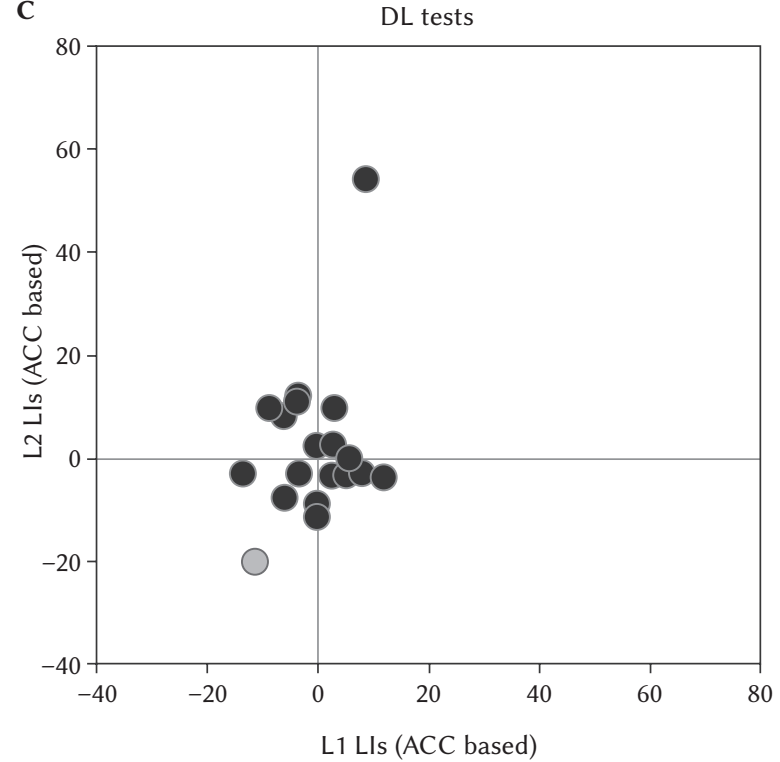

B

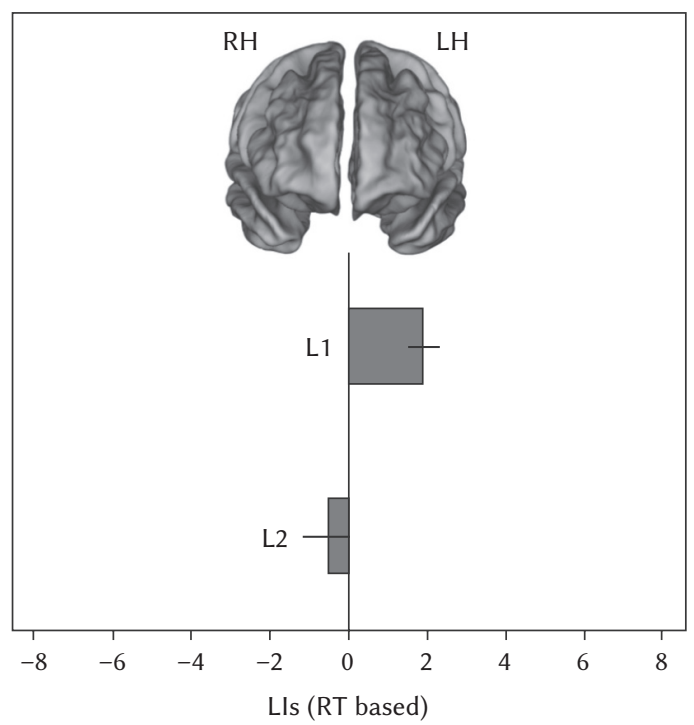

D

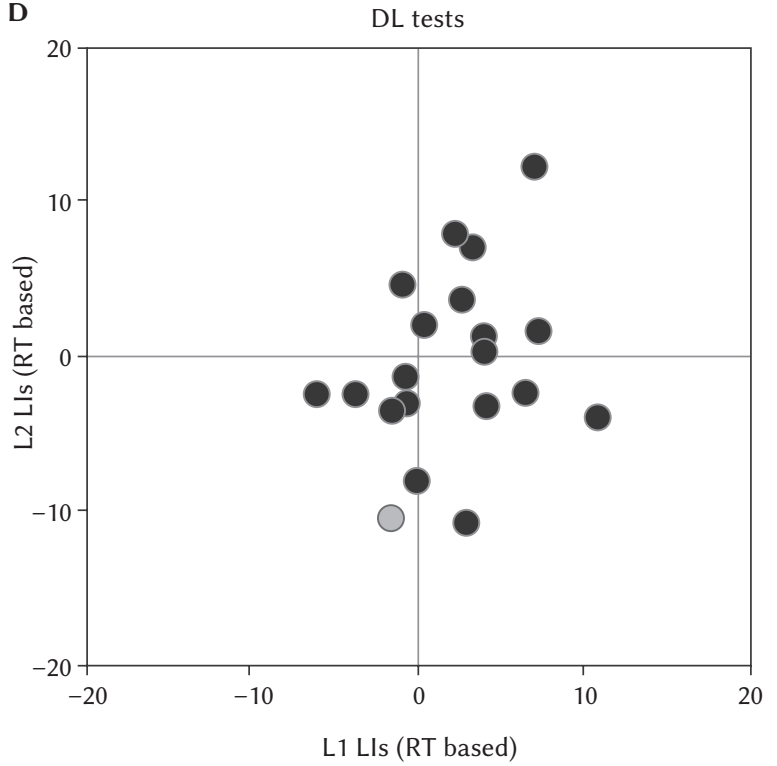

Figure 6. Hemispheric organization (laterality indices, LIs) of processing for auditorily presented action words in the first language (Polish, L1) and second language (English, L2). (A) Accuracy (ACC)-based LIs: No significant differences between lateralization of action word processing in L1 and L2. (B) Response-time (RT)-based LIs: There is a trend, rather than a significant difference between lateralization of action word processing in L1 and L2. (C) Individual ACC-based LIs: There were no significant correlations between lateralization of action word processing in L1 and L2. (D) Individual RT-based LIs: There were no significant correlations between lateralization of action word processing in L1 and L2. LH - left hemisphere, $\mathrm{RH}-$ right hemisphere; DL - dichotic listening; black dots - right-handed participants; gray dot - left-handed participant. Error bars depict standard errors of the means. 
Figure $8 \mathrm{~A}-\mathrm{B}$ shows a significant right ear/left hemispheric advantage for tool sounds named in L1, as compared to L2, but only for ACC-based LIs (difference between means $=8.13, S E=3.54$, $t(19)=2.30, p<.05$; for RT-based LIs $t(19)=1.00$, $p>.05)$. Moreover, as Figure 8C-D shows, there were non-significant trends, but no significant correlations between individuals' L1 and L2 LIs, for both ACC-based LIs $(r=.15, p=.542)$ and RT-based LIs $(r=.29, p=.214)$.

\section{LATERALITY OF VISUALLY PRESENTED \\ ACTION WORD PROCESSING VERSUS AUDITORILY PRESENTED ACTION WORD AND TOOL SOUND PROCESSING}

Figure 9A shows that for ACC there was a main effect of test type $(F(2,38)=24.95, p<.001)$, such that we observed a significant left hemispheric advantage for VHF, as compared to both DL tests (i.e., for visually presented action word processing vs. auditorily pre-

Tool-sound processing in a bilingual brain
A

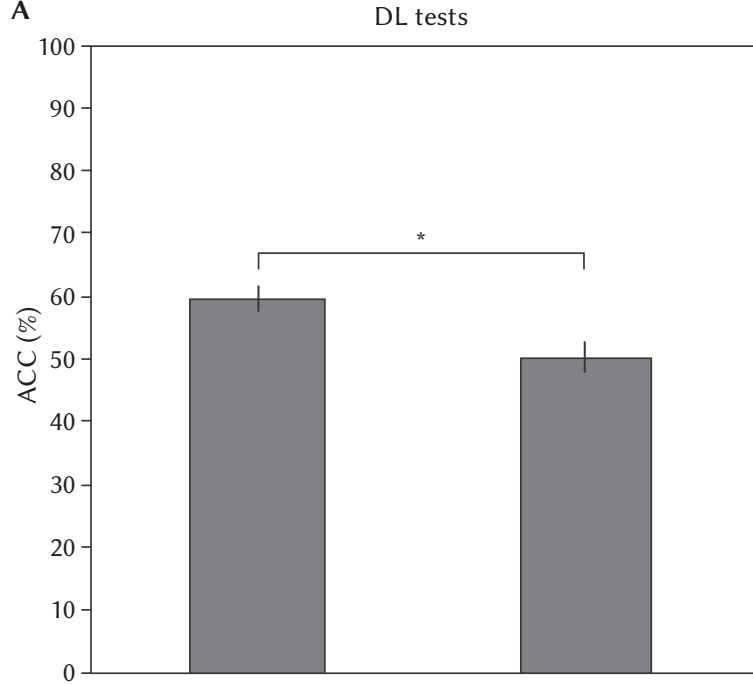

L1

C

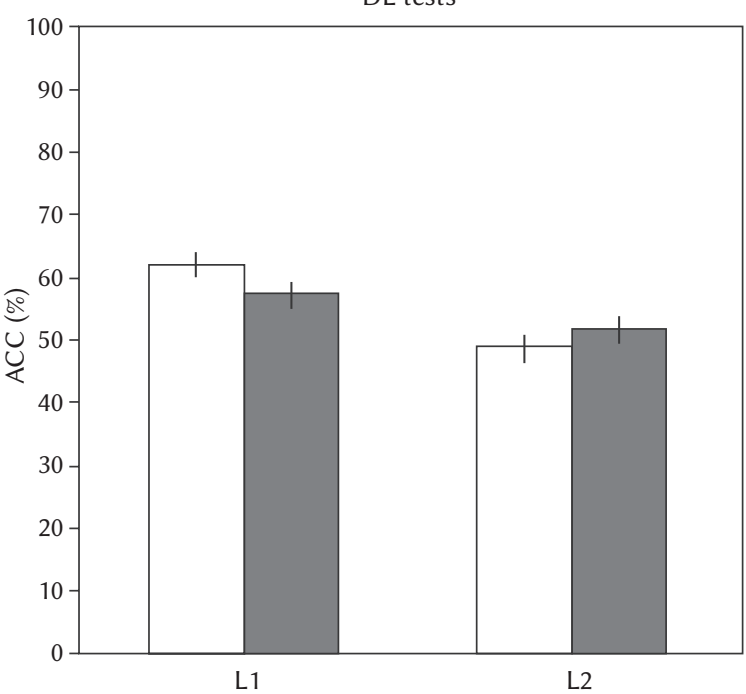

B

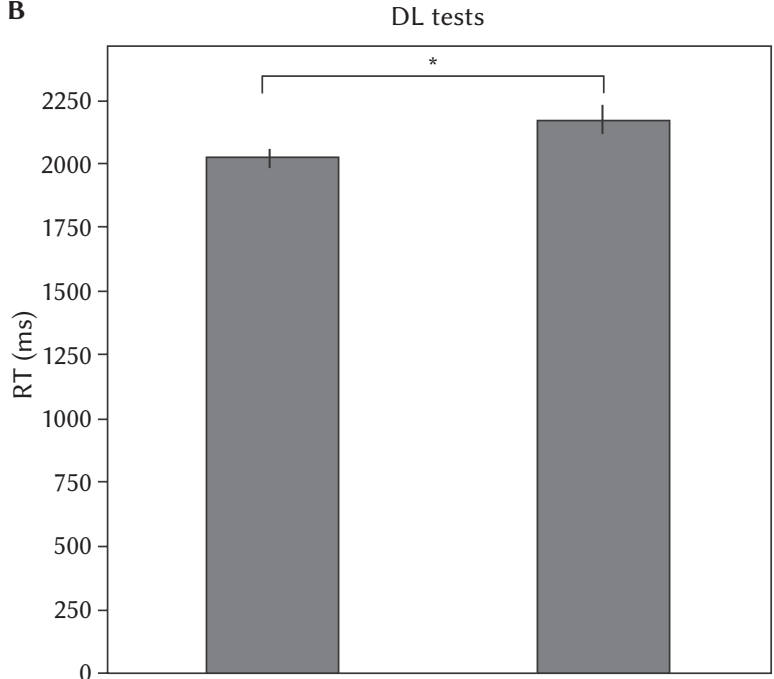

L1

D

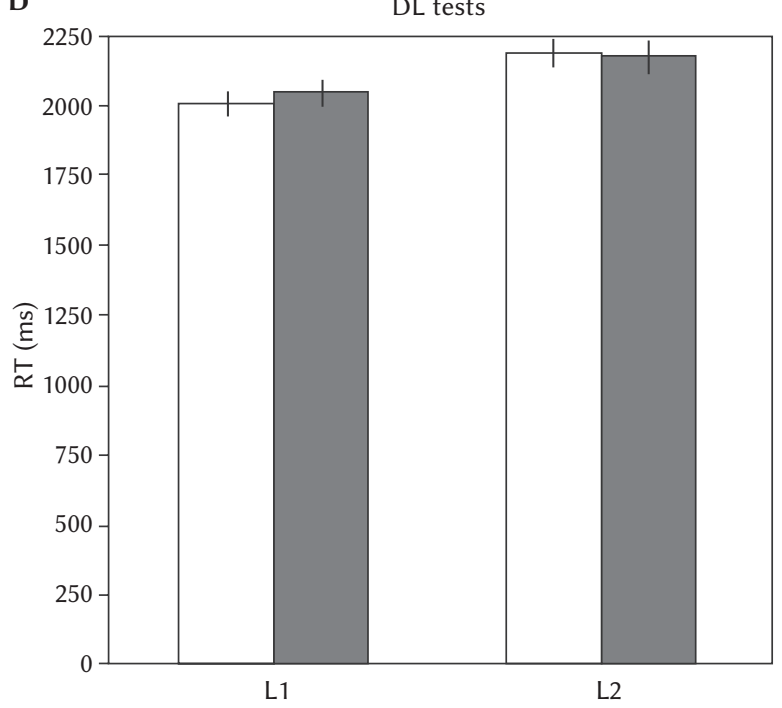

$\square$ RE

LE

Figure 7. Dichotic listening (DL) processing of tool sounds. (A) Differences between accuracy (ACC) for tool sound naming in the first language (Polish, L1) and second language (English, L2): ACC was significantly better for L1. (B) Differences between response times (RTs) for correctly named tool sounds in L1 and L2: RTs were significantly faster for L1. (C) Differences between ACC for tool sound naming presented in right ear (RE) and left ear (LE): No significant effects both for L1 and in L2. (D) Differences between RTs for correctly named tool sounds presented in RE and LE: No significant effects both for L1 and in L2. Asterisks indicate the only significant results, with ${ }^{*}$ referring to $p<.05$. Error bars depict standard errors of the means. 
sented action word processing: difference between means $=25.10, S E=4.38, B f-p<.001$; visually presented action word processing versus tool sound processing: difference between means $=25.35, S E=4.66$, $B f-p<.001$; auditorily presented action word processing versus tool sound processing: no significant differences, $B f-p>.05)$. Nevertheless, there was no main effect of language $(F(1,19)=3.50, p>.05)$ and the test type by language interaction was not significant, either $(F(2,38)=2.53, p>.05)$.

Figure 9B shows that for RT there was also a main effect of test type $(F(2,38)=7.77, p<.01)$, such that (similarly to ACC) we observed a significant left hemispheric advantage for VHF, as compared to both DL
Michal Klichowski, Agnieszka Nowik, Gregory Kroliczak, James W. Lewis
A

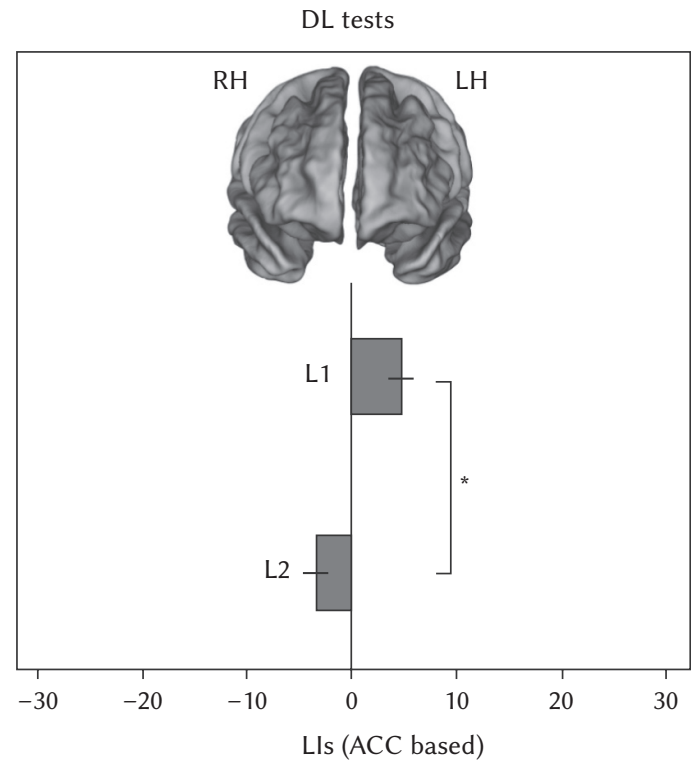

C

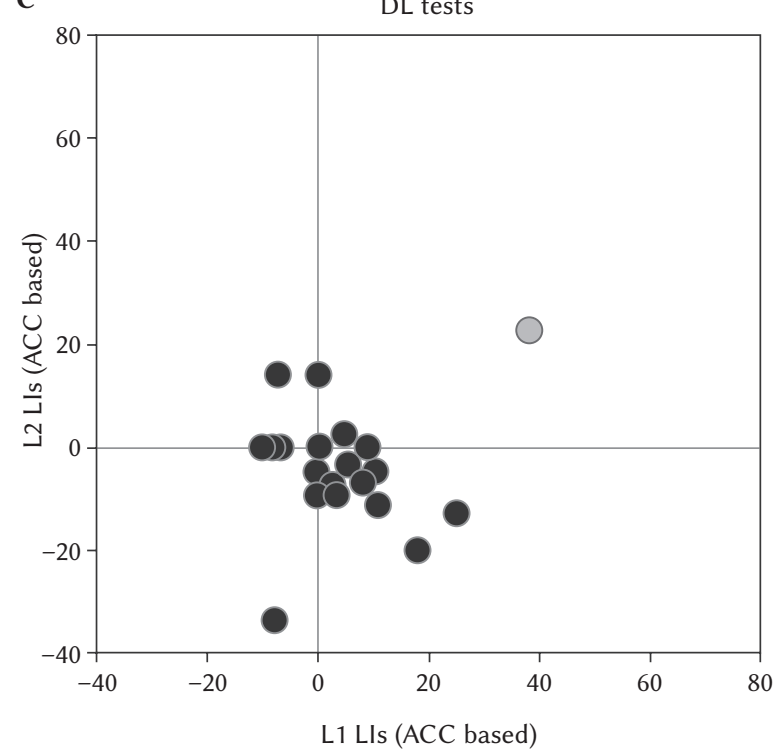

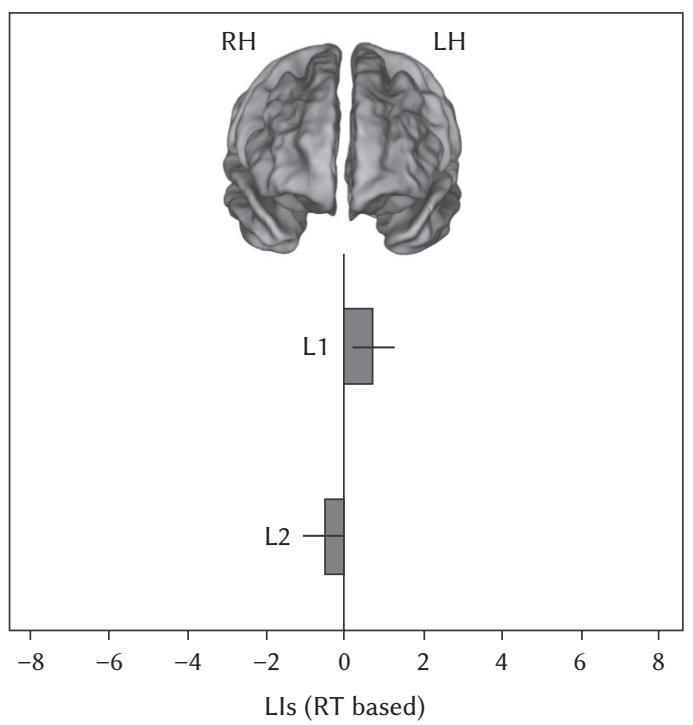

D

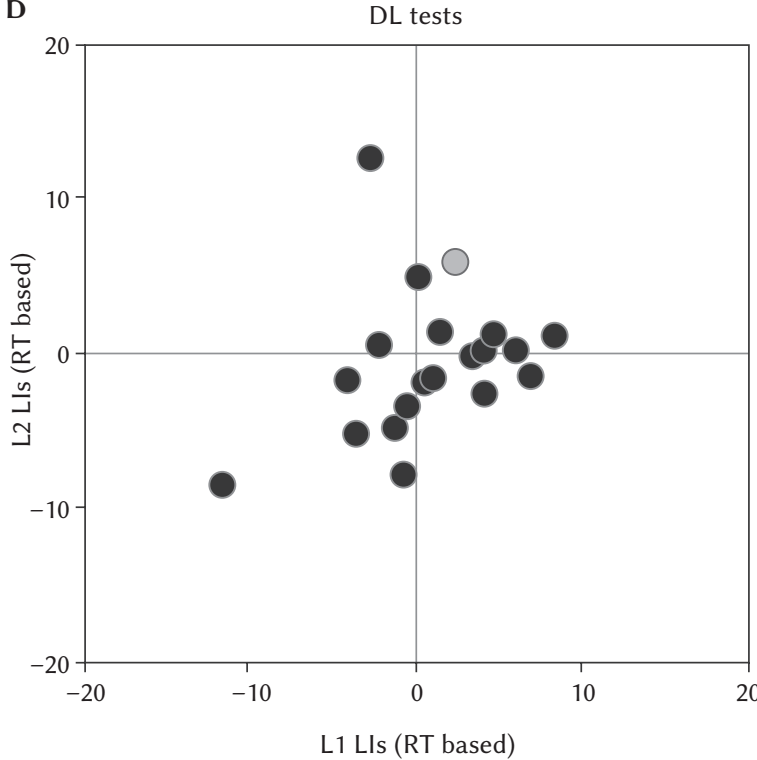

Figure 8. Hemispheric organization (laterality indices, LIs) of processing tool sounds. (A) Accuracy (ACC)based LIs: There was a significant left hemispheric (LH) advantage for tool sound naming in the first language (Polish, L1), as compared to second language (English, L2). (B) Response-time (RT)-based LIs: No significant differences between lateralization of tool sound naming in L1 and L2. (C) Individual ACC-based LIs: There were no significant correlations between lateralization of tool sound naming in L1 and L2. (D) Individual RT-based LIs: There were no significant correlations between lateralization of tool sound naming in L1 and L2. LH - left hemisphere, RH - right hemisphere; DL - dichotic listening; black dots - right-handed participants; gray dot - left-handed participant. Asterisks indicate significant $p$-values: ${ }^{*} p<.05$. Error bars depict standard errors of the means. 


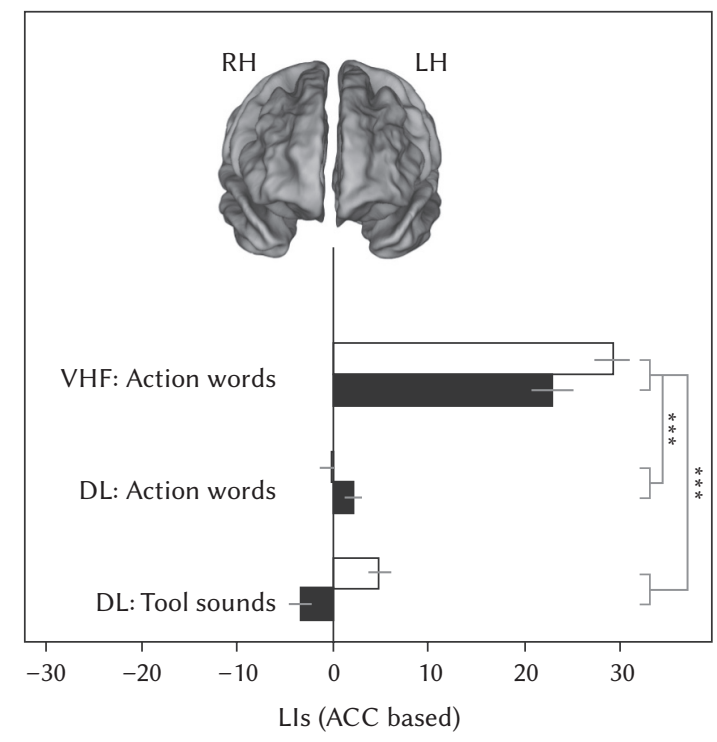

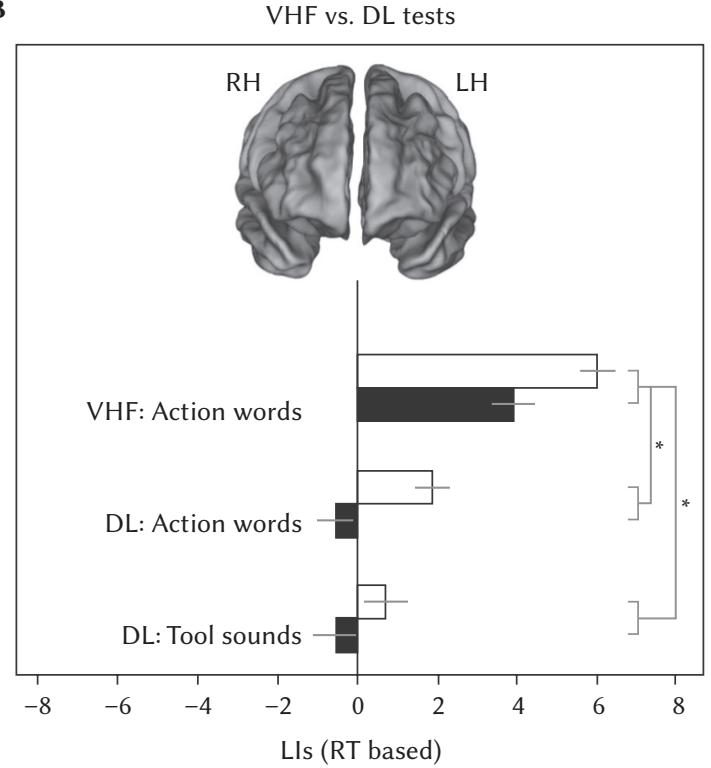

Tool-sound processing in a bilingual brain

Figure 9. Hemispheric organization (laterality indices, LIs) of processing for visually presented action words versus auditorily presented action words and tool sounds. (A) Accuracy (ACC)-based LIs: There was a significant left hemispheric ( $\mathrm{LH}$ ) advantage for visually presented action word processing, as compared to auditorily presented action words, and also as compared to tool sounds, both in the first language (Polish, L1) and second language (English, L2). There were no significant differences between lateralization of processing for auditorily presented action words and tool sounds. (B) Reaction-time (RT)-based LIs: There was also a significant left hemispheric (LH) advantage for visually presented action word processing, as compared to auditorily presented action words, and also as compared to tool sounds, both in L1 and L2. However, there were no significant differences between lateralization of processing for auditorily presented action words and tool sounds. (C) Individual ACC-based LIs: There were no significant correlations between lateralization of visually presented action word processing in L1 and auditorily presented action word processing in L1. (D) Individual RT-based LIs: There were no significant correlations between lateralization of visually presented action word processing in L1 and auditorily presented action word processing in L1. (E) Individual ACC-based LIs: There were no significant correlations between lateralization of visually presented action word processing in L1 and tool sound naming in L1. (F) Individual RT-based LIs: There were no significant correlations between lateralization of visually presented action word processing in $\mathrm{L} 1$ and tool sound naming in L1. (G) Individual ACC-based LIs: There were no significant correlations between lateralization of auditorily presented action word processing in L1 and tool sound naming in L1. (H) Individual RT-based LIs: There were no significant correlations between lateralization of auditorily presented action word processing in L1 and tool sound naming in L1. (I) Individual ACC-based LIs: There were no significant correlations between lateralization of visually presented action word processing in $\mathrm{L} 2$ and auditorily presented action word processing in L2. (J) Individual RT-based LIs: There were no significant correlations between lateralization of visually presented action word processing in L2 and auditorily presented action word processing in L2. (K) Individual ACC-based LIs: There were no significant correlations between lateralization of visually presented action word processing in L2 and tool sound naming in L2. (L) Individual RT-based LIs: There were significant correlations between lateralization of visually presented action word processing in L2 and tool sound naming in L2. (M) Individual ACC-based LIs: There were no significant correlations between lateralization of auditorily presented action word processing in L2 and tool sound naming in L2. (N) Individual RT-based LIs: There were no significant correlations between lateralization of auditorily presented action word processing in L2 and tool sound naming in L2. LH - left hemisphere, RH - right hemisphere; VHF - visual half-field; DL - dichotic listening; black dots - right-handed participants; gray dot - left-handed participant. Asterisks indicate significant $p$-values: ${ }^{*} p<.05,{ }^{* *} p<.001$. Error bars depict standard errors of the means.

(Figure 9 continues) 
Michal Klichowski, Agnieszka Nowik, Gregory Kroliczak, James W. Lewis
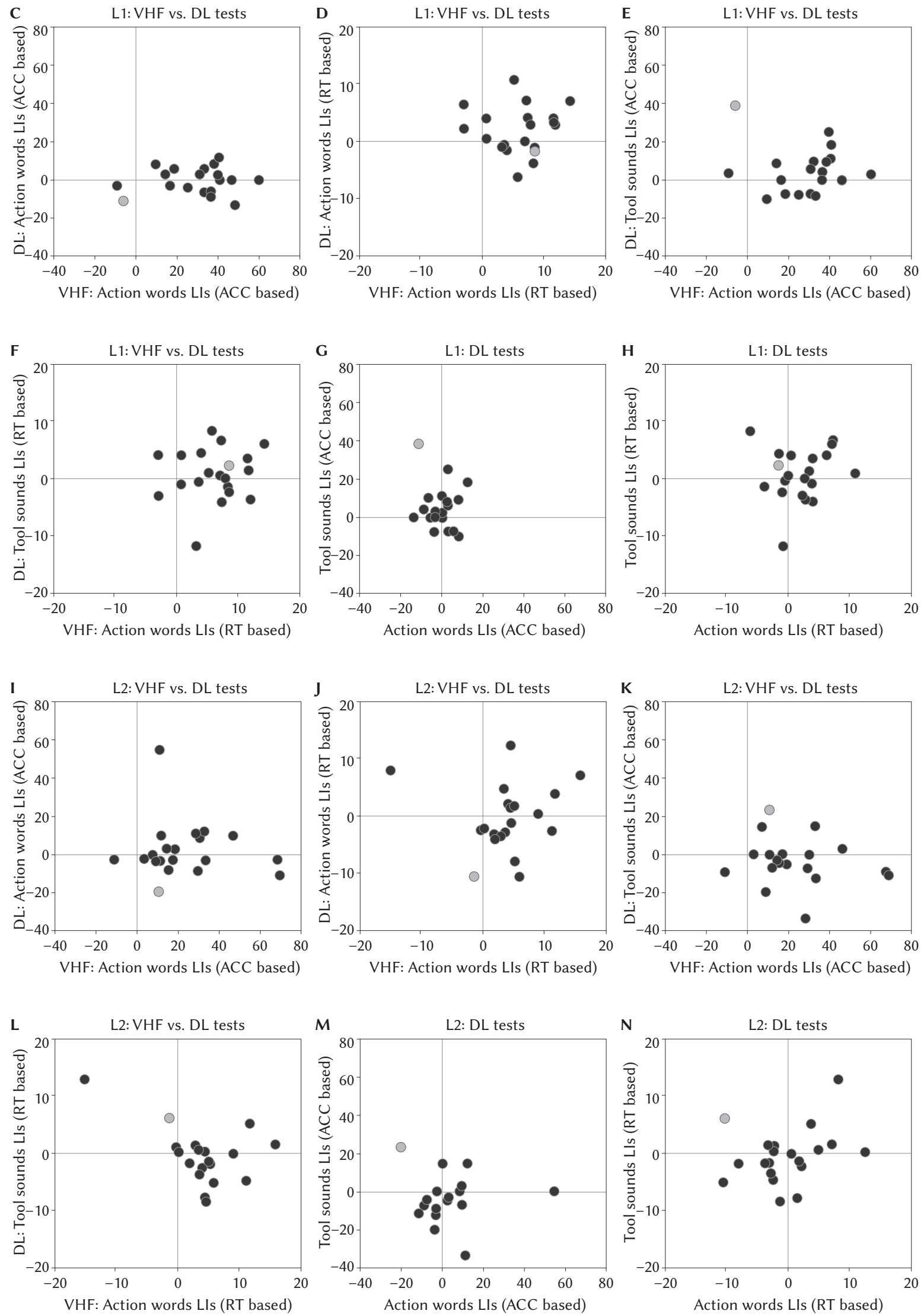

Figure 9.

(Figure 9 continued) 
tests (i.e., for visually presented action word processing vs. auditorily presented action word processing: difference between means $=4.22, S E=1.39, B f-p<.05$; visually presented action word processing versus tool sound processing: difference between means $=4.84$, $S E=1.50, B f-p<.05$; auditorily presented action word processing versus tool sound processing: no significant differences, $B f-p>.05)$. However, for RT we also observed a main effect of language $(F(1,19)=7.60$, $p<.05)$, such that L2 was less left lateralized as compared to L1 (difference between means $=1.93, S E=0.70$, $B f-p<.05)$. Nevertheless, the test type by language interaction was not significant $(F(2,38)=0.22, p>.05)$.

Moreover, we found that there were no significant correlations between individuals' LIs for visually presented action-word processing and all kinds of processing for auditorily presented stimuli, and even for auditorily presented action-word processing and tool-sound processing. This effect was found for both ACC-based LIs $(r<.17$ in all cases, all $p$-s $>.05)$ and RT-based LIs $(r<.29$ in all cases, all $p$-s $>.05$, with the exception of one situation when $r=.49$ and $p=.027$ : LIs for visually presented action word processing in L2 and LIs for tool sound naming in L2, see Figure 9L) and these results are shown in Figure 9C-N.

\section{DISCUSSION}

Consistent with numerous fMRI studies (e.g. Hunter \& Brysbaert, 2008) showing that the VHF paradigm is a good measure of cerebral language dominance, our current study demonstrated that, despite some variability, bilinguals have productive language typically lateralized (to the left hemisphere), and in line with the results of our previous study (Krefta et al., 2015) that both languages (L1 and L2) have similar organization in their brains (there is clear co-lateralization). As expected, though, bilinguals showed atypical (hemispherically balanced) organization of processing action-related sounds, that is both in the form of action words as such, and tool sounds (irrespective of the language that they used to identify a given sound). However, there were no correlations between LIs for language processing and LIs for action-related sound processing. What is more surprising, though, is that there were no correlations between LIs for auditory processing of action words and LIs for tool sound processing, either. It thus seems that in the bilingual brain these three functions might be neurally independent.

\section{CO-LATERALIZATION OF LANGUAGES IN THE BILINGUAL BRAIN}

Neuroimaging studies on language processing in the bilingual brain show many contradictions (Liu \& Cao, 2016). On the one hand, there is some evidence that
L2 is organized in the brain like L1, i.e. that L2 uses the same brain network that L1 does (e.g. Nakada, Fujii, \& Kwee, 2001; Tan et al., 2003). On the other hand, there is also evidence that L2 processing can take place in a different cortical network than L1, and that for processing of L2 there is weaker lateralization as compared to L1 (Nelson, Liu, Fiez, \& Perfetti, 2009; Huang, Itoh, Kwee, \& Nakada, 2012; Park, BadzakovaTrajkov, \& Waldie, 2012). Our results for language production (reading words in VHF tests) are thus in line with the first group of reports which suggest a common brain network for L1 and L2, and unambiguously corroborate the existence of the co-lateralization of L1 and L2 in the bilingual brain demonstrated in our previous study (Krefta et al., 2015). This is at variance with reports showing that the processing of L2 is more hemispherically balanced than that of L1. In a somewhat differently designed VHF experiment with bilinguals (Willemin et al., 2016) similar results were obtained, yet there was a right hemisphere shift observed in early, as compared to late bilinguals. These outcomes then suggest that our observations are characteristic for late bilingualism.

Nevertheless, in spite of the lack of significant differences between the LIs of L1 and L2, and a strong correlation between them, we found that bilinguals processed words in L2 more slowly (on average, $118 \mathrm{~ms}$ slower) as compared to L1. It was definitely not a consequence of lower fluency because for VHF tests there were no differences between ACC for L1 and L2 (ACC asymmetry would indicate a mediating role of proficiency; see Felton et al., 2017). This is in line with the Inhibitory Control Model. It shows that before using L2 in the bilingual brain, stronger control mechanisms occur as compared to L1, which makes the reaction time longer (Wu \& Thierry, 2017; Felton et al., 2017). It is linked to the fact that before using L2, the language control network has to hinder (automatically activated) L1 (Grundy et al., 2017).

\section{FUNCTIONAL ORGANIZATION OF ACTION-RELATED SOUND PROCESSING IN THE BILINGUAL BRAIN}

In DL experiments where verbal material is used, lefthemispheric dominance is commonly observed, irrespective of sex, age or language (for example, see the study by Bless et al., 2015, on over 4000 participants with more than 60 different language backgrounds, or the meta-analysis by Kimura, 2011). A general model of processing speech sounds also shows that this mechanism should be strongly left-lateralized (Friederici, 2002, 2011; Friederici \& Alter, 2004; Dotan \& Friedmann, 2015). Thus, our study on processing auditorily presented action words suggests that bilinguals have a different (more hemispherically balanced) organization of speech-specific sounds from
Tool-sound processing in a bilingual brain 
Michal Klichowski, Agnieszka Nowik, Gregory Kroliczak, James W. Lewis monolinguals. This observation is in line with the neuroimaging study by Kuhl et al. (2016) where the participants were Spanish-English bilingual and native English-speaking monolingual adults.

However, despite the lack of significant differences between the LIs of L1 and L2 for processing auditorily presented action words (with some non-significant tendencies, though), there was no correlation between them. This suggests that bilinguals process speechspecific sounds in L1 and L2 differently, and that the functional organization of speech sound processing (see Hickok \& Poeppel, 2000, 2007; see also Hickok \& Poeppel, 2015) in the bilingual brain is influenced by the language used. It is probably not due to the structure of L1 and L2 or distance between L1 and L2 (which can influence the level of lateralization; see van der Noort et al., 2014; Kim et al., 2016), because, as our VHF tests show, there was co-lateralization of L1 and L2 representations. In the bilingual brain, different languages are thus probably not organized differently (see Hull \& Vaid, 2007; Peng \& Wang, 2011), whereas sounds of different languages are.

The case is similar for tool sounds. Although processing these sounds should be lateralized (see Lewis et al., 2005, 2006), in bilinguals their processing (irrespective of the language of response) was hemispherically balanced (yet, with some trends). Moreover, the LIs for L1 and L2 for tool sounds were not correlated. The functional organization of tool sound processing in the bilingual brain, therefore, also seems to depend on the language in use.

Our study then shows that the functional lateralization of action-related sound (whether verbal, e.g. action words, or non-verbal, e.g. tool sounds) processing is influenced by bilingual experience. This conclusion thus supports the thesis that bilingualism changes the functional organization of sound processing in the brain (Skoe et al., 2017), as well as a broader hypothesis that bilingualism causes neuroplastic (adaptive) changes in the human brain (Garcia-Penton et al., 2014; Burgaleta et al., 2016; Grundy et al., 2017), and that there are cortical correlates of bilingualism that can be observed (Felton et al., 2017).

\section{FUNCTIONAL INDEPENDENCIES IN THE BILINGUAL BRAIN}

The comparison of LIs for visually presented action words with LIs for auditorily presented action words and tool sound processing shows that these functions might be neurally independent to some extent, as there are no correlations whatsoever. (High variability, but in some cases also little variability, might be other contributing factors.) Thus, unless both of these tasks are more linguistic in nature, these findings are not in line with neuropsychological and neuroimaging evidence that shows a close link between the representa- tions of praxis and language in the human brain ( $\mathrm{Fa}-$ diga et al., 2002; D’Ausilio et al., 2009; Kroliczak et al., 2011; see also Kroliczak, Westwood, \& Goodale, 2006). This suggests that bilinguals, unlike monolinguals (see Bernardis \& Gentilucci, 2006; Gentilucci \& Corballis, 2006; Gentilucci, Campione, Dalla Volta, \& Bernardis, 2009; Pulvermuller \& Fadiga, 2010), when processing different action-related sounds, use different brain networks which to some extent are independent from the language production brain network.

The paradigms used in this study, however, only serve the purpose of measuring hemispheric asymmetry (Kimura, 2011). We thus do not know if an atypical lateralization of sound processing in the bilingual brain means a larger share of homologous traditional areas from the right hemisphere (Friederici, 2002; Friederici \& Alter, 2004; Pulvermuller \& Fadiga, 2010), as is the case, for example, when the right hemisphere takes over (in a mirror-image fashion) the functions of language areas in the left hemisphere if they are injured or destroyed in early childhood (Tivarus, Starling, Newport, \& Langfitt, 2012; cf. Liegeois, Connelly, Baldeweg, \& VarghaKhadem, 2008). This may mean that the representations of sound processing in the bilingual brain have unique neural characteristics, similarly to unique organization of productive language in atypical cases (Bidula et al., 2017; see also Corballis, 2003; Vingerhoets et al., 2013; Gainotti, 2015; Haberling \& Corballis, 2015; Badzakova-Trajkov, Corballis, \& Haberling, 2016), or representations of praxis in people who use a tool professionally, e.g. in tennis players (Biggio, Bisio, Avanzino, Ruggeri, \& Bove, 2017). We could then talk about the existence of many unique sound brain networks in the bilingual brain. In order to settle this issue, it is necessary to conduct further studies that use neuroimaging methods (and such a continuation of VHF and DL studies is also suggested by the authors of these paradigms, see Kimura, 2011). Furthermore, only neuroimaging studies may corroborate that behavioral effects observed in our experiment are indeed related to unique organization of the bilingual brain. Of course, bilingual experience might also benefit a plethora of other cognitive processes, including executive functions, particularly the control and inhibition mechanism (Hartanto \& Yang, 2019).

\section{CONCLUSIONS AND POSSIBLE CLINICAL IMPORTANCE}

Our findings show that action-related sound processing (whether verbal or non-verbal) in bilinguals is not (as is the case in monolinguals) left-lateralized, but it is hemispherically more balanced. Furthermore, for sound processing bilinguals use many diverse neural networks, to some extent independent of the language production brain network. The functional organiza- 
tion of sound processing in the bilingual brain thus seems to be rather more complex and plastic than that in the monolingual brain. Therefore, the bilingual brain should more easily (than the monolingual one) adapt in patients with damage in brain areas associated with sound-related functions (apart from those associated with speech production). Such a conclusion is in line with a study by Alladi et al. (2016), who found that post-stroke, cognitive functions remain intact considerably more often in bilinguals than in monolinguals (with the exception of aphasia). Thus, our findings support the broad thesis that bilingualism, as well as intensive new/second language learning, may protect one from the development of some post-stroke cognitive impairments (Alladi et al., 2016) and in ageing healthy elderly people may, for example, delay the onset of dementia symptoms (Bak, Long, Vega-Mendoza, \& Sorace, 2016; Bialystok, Abutalebi, Bak, Burke, \& Kroll, 2016). In sum, our findings shed new light not only on the functional organization of the bilingual brain, but also on general mechanisms of brain plasticity and emphasize even more the potential of non-native language learning for brain health and neurorehabilitation.

\section{ACKNOWLEDGMENTS}

This work was a part of a greater project supported by the Polish National Science Center MAESTRO grant 2011/02/A/HS6/00174 to Gregory Kroliczak, and internal university founds (S/P-B/NS/176) provided by the Ministry of Science and Higher Education (MNiSW). During the preparation of this manuscript Agnieszka Nowik and Gregory Kroliczak were supported by the Maestro grant, while Michal Klichowski was supported by European Cooperation in Science and Technology grant: European Network on Brain Malformations (Neuro-MIG) (CA COST Action CA16118) and by scholarship for young outstanding scientists funded by the Ministry of Science and Higher Education in Poland (0049/E-336/STYP/11/2016). The equipment used was funded by MNiSW grant 6168/IA/128/2012 to Gregory Kroliczak.

\section{ENDNOTE}

1 Hunter and Brysbaert (2008) suggested that in VHF studies the stimuli should not be visible for more than 200 ms. Earlier studies from our laboratory (Klichowski \& Kroliczak, 2017; Krefta et al., 2015) have demonstrated that, with the adopted parameters of the procedure and stimulus characteristics, a target duration of $217 \mathrm{~ms}$ leads to the required response accuracy of approximately 75\% (see also McNair \& Harris, 2012; but cf. Helon \& Kroliczak, 2014).

\section{References}

Alladi, S., Bak, T. H., Mekala, S., Rajan, A., Chaudhuri, J. R., Mioshi, E., Krovvidi, R., Surampudi, B., Duggirala, V., \& Kaul, S. (2016). Impact of bilingualism on cognitive outcome after stroke. Stroke, 47, 258-261. https://doi.org/10.1161/STROKEAHA.115.010418

Badzakova-Trajkov, G., Corballis, M. C., \& Haberling, I. S. (2016). Complementarity or independence of hemispheric specializations? A brief review. Neuropsychologia, 93, 386-393. https://doi. org/10.1016/j.neuropsychologia.2015.12.018

Bak, T. H., Long, M. R., Vega-Mendoza, M., \& Sorace, A. (2016). Novelty, challenge, and practice: The impact of intensive language learning on attentional functions. PLoS One, 11, e0153485. https:// doi.org/10.1371/journal.pone.0153485

Bechtold, L., Ghio, M., Antoch, G., Turowski, B., Wittsack, H. J., Tettamanti, M., \& Bellebaum, C. (2019). How words get meaning: The neural processing of novel object names after sensorimotor training. Neurolmage, 197, 284-294. https://doi.org/10.1016/j. neuroimage.2019.04.069

Bernardis, P., \& Gentilucci, M. (2006). Speech and gesture share the same communication system. Neuropsychologia, 44, 178-190. https://doi.org/10.1016/j. neuropsychologia.2005.05.007

Bialystok, E., Abutalebi, J., Bak, T. H., Burke, D. M., \& Kroll, J. F. (2016). Aging in two languages: Implications for public health. Ageing Research Reviews, 27, 56-60. https://doi.org/10.1016/j.arr.2016.03.003

Bidula, S. P., \& Kroliczak, G. (2015). Structural asymmetry of the insula is linked to the lateralization of gesture and language. European Journal of $\mathrm{Neu}$ roscience, 41, 1438-1447. https://doi.org/10.1111/ ejn. 12888

Bidula, S. P., Przybylski, L., Pawlak, M. A., \& Kroliczak, G. (2017). Unique neural characteristics of atypical lateralization of language in healthy individuals. Frontiers in Neuroscience, 11, 1-21. https:// doi.org/10.3389/fnins.2017.00525

Biggio, M., Bisio, A., Avanzino, L., Ruggeri, P., \& Bove, M. (2017). This racket is not mine: The influence of the tool-use on peripersonal space. $\mathrm{Neu}$ ropsychologia, 103, 54-58. https://doi.org/10.1016/j. neuropsychologia.2017.07.018

Binkofski, F., \& Buccino, G. (2004). Motor functions of the Broca's region. Brain and Language, 89, 362-369. https://doi.org/10.1016/S0093-934X(03)00358-4

Bless, J. J., Westerhausen, R., von Koss Torkildsen, J., Gudmundsen, M., Kompus, K., \& Hugdahl, K. (2015). Laterality across languages: Results from a global dichotic listening study using a smartphone application. Laterality, 20, 434-452. https:// doi.org/10.1080/1357650X.2014.997245

Bornkessel-Schlesewsky, I., Schlesewsky, M., \& von Cramon, D. Y. (2009). Word order and Broca's region: Evidence for a supra-syntactic perspective.
Tool-sound processing in a bilingual brain 
Michal Klichowski, Agnieszka Nowik, Gregory Kroliczak, James W. Lewis
Brain and Language, 111, 125-139. https://doi. org/10.1016/j.bandl.2009.09.004

Bourquin, N. M., Simonin, A., \& Clarke, S. (2013). Repetition-induced plasticity of motor representations of action sounds. Brain Topography, 26, 152-156. https://doi.org/10.1007/s10548-012-0260-z

Buccino, G., Riggio, L., Melli, G., Binkofski, F., Gallese, V., \& Rizzolatti, G. (2005). Listening to action-related sentences modulates the activity of the motor system: a combined TMS and behavioral study. Cognitive Brain Research, 24, 355-363. https://doi.org/10.1016/j.cogbrainres.2005.02.020

Burgaleta, M., Sanjuan, A., Ventura-Campos, N., Sebastian-Galles, N., \& Avila, C. (2016). Bilingualism at the core of the brain. Structural differences between bilinguals and monolinguals revealed by subcortical shape analysis. Neurolmage, 125, 437-445. https://doi.org/10.1016/j.neuroimage.2015.09.073

Clarke, S., \& Geiser, E. (2015). Roaring lions and chirruping lemurs: How the brain encodes sound objects in space. Neuropsychologia, 75, 304-313. https://doi. org/10.1016/j.neuropsychologia.2015.06.012

Corballis, M. C. (2003). From mouth to hand: Gesture, speech, and the evolution of right-handedness. Behavioral and Brain Sciences, 26, 199-208. https://doi.org/10.1017/S0140525X03000062

Corballis, M. C. (2010). Mirror neurons and the evolution of language. Brain and Language, 112, 25-35. https://doi.org/10.1016/j.bandl.2009.02.002

Corballis, M. C. (2017) The evolution of lateralized brain circuits. Frontiers in Psychology, 8, 1021. https://doi.org/10.3389/fpsyg.2017.01021

Costa, A., \& Sebastian-Galles, N. (2014). How does the bilingual experience sculpt the brain? Nature Reviews Neuroscience, 15, 336-345. https://doi.org/ 10.1038/nrn3709

Crivelli, D., Rueda, M. S., \& Balconi, M. (2018). Linguistic and motor representations of everyday complex actions: an fNIRS investigation. Brain Structure and Function, 223, 2989-2997. https://doi.org/10.1007/ s00429-018-1646-9

D’Ausilio, A., Pulvermuller, F., Salmas, P., Bufalari, I., Begliomini, C., \& Fadiga, L. (2009). The motor somatotopy of speech perception. Current Biology, 19, 381-385. https://doi.org/10.1016/j.cub.2009.01.017

de Borst, A. W., Valente, G., Jaaskelainen, I. P., \& Tikka, P. (2016). Brain-based decoding of mentally imagined film clips and sounds reveals experiencebased information patterns in film professionals. Neurolmage, 129, 428-438. https://doi.org/10.1016/j. neuroimage.2016.01.043

Dotan, D., \& Friedmann, N. (2015). Steps towards understanding the phonological output buffer and its role in the production of numbers, morphemes, and function words. Cortex, 63, 317-351. https:// doi.org/10.1016/j.cortex.2014.08.014

Dragovic, M. (2004). Towards an improved measure of the Edinburgh Handedness Inventory: a one- factor congeneric measurement model using confirmatory factor analysis. Laterality, 9, 411-419. https://doi.org/10.1080/13576500342000248

Duffy, M., Waitt, G., \& Harada, T. (2016). Making sense of sound: Visceral sonic mapping as a research tool. Emotion, Space and Society, 20, 49-57. https://doi.org/10.1016/j.emospa.2016.06.006

Fadiga, L., Craighero, L., Buccino, G., \& Rizzolatti, G. (2002). Speech listening specifically modulates the excitability of tongue muscles: a TMS study. European Journal of Neuroscience, 15, 399-402. https://doi.org/10.1046/j.0953-816x.2001.01874.x

Felton, A., Vazquez, D., Ramos-Nunez, A. I., Greene, M. R., McDowell, A., Hernandez, A. E., \& Chiarello, C. (2017). Bilingualism influences structural indices of interhemispheric organization. Journal of Neurolinguistics, 42, 1-11. https:// doi.org/10.1016/j.jneuroling.2016.10.004

Fischer, M. H., \& Zwaan, R. A. (2008). Embodied language: a review of the role of the motor system in language comprehension. The Quarterly Journal of Experimental Psychology, 61, 825-850. https://doi. org/10.1080/17470210701623605

Friederici, A. D. (2002). Towards a neural basis of auditory sentence processing. Trends in Cognitive Science, 6, 78-84. https://doi.org/10.1016/S13646613(00)01839-8

Friederici, A. D. (2011). The brain basis of language processing: From structure to function. Physiological Reviews, 91, 1357-1392. https://doi.org/10.1152/ physrev.00006.2011

Friederici, A. D., \& Alter, K. (2004). Lateralization of auditory language functions: a dynamic dual pathway model. Brain and Language, 89, 267-276. https://doi.org/10.1016/S0093-934X(03)00351-1

Gainotti, G. (2015). The influence of handedness on hemispheric representation of tools: a survey. Brain and Cognition, 94, 10-16. https://doi.org/10.1016/j. bandc.2014.12.005

Galati, G., Committeri, G., Spitoni, G., Aprile, T., Di Russo, F., Pitzalis, S., \& Pizzamiglio, L. (2008). A selective representation of the meaning of actions in the auditory mirror system. Neurolmage, 40, 1274-1286. https://doi.org/10.1016/j.neuroimage.2007.12.044

Garcia-Penton, L., Perez Fernandez, A., Iturria-Medina, Y., Gillon-Dowens, M., \& Carreiras, M. (2014). Anatomical connectivity changes in the bilingual brain. Neurolmage, 84, 495-504. https://doi. org/10.1016/j.neuroimage.2013.08.064

Gentilucci, M., Campione, G. C., Dalla Volta, R., \& Bernardis, P. (2009). The observation of manual grasp actions affects the control of speech: a combined behavioral and Transcranial Magnetic Stimulation study. Neuropsychologia, 47, 3190-3202. https:// doi.org/10.1016/j.neuropsychologia.2009.07.020

Gentilucci, M., \& Corballis, M. C. (2006). From manual gesture to speech: a gradual transition. $\mathrm{Neu}$ - 
roscience \& Biobehavioral Reviews, 30, 949-960. https://doi.org/10.1016/j.neubiorev.2006.02.004

Grundy, J. G., Anderson, J. A. E., \& Bialystok, E. (2017). Bilinguals have more complex EEG brain signals in occipital regions than monolinguals. Neurolmage, 159, 280-288. https://doi.org/10.1016/j.neuroimage.2017.07.063

Haberling, I. S., \& Corballis, M. C. (2015). Cerebellar asymmetry, cortical asymmetry and handedness: Two independent networks. Laterality, 19, 1-18. https://doi.org/10.1080/1357650X.2015.1110161

Haberling, I. S., Corballis, P. M., \& Corballis, M. C. (2016). Language, gesture, and handedness: Evidence for independent lateralized networks. Cortex, 82, 72-85. https://doi.org/10.1016/j.cortex.2016.06.003

Hartanto, A., \& Yang, H. (2019). Does early active bilingualism enhance inhibitory control and monitoring? A propensity-matching analysis. Journal of Experimental Psychology: Learning, Memory, and Cognition, 45, 360-378. https://doi.org/10.1037/ $x \operatorname{lm} 0000581$

Helmich, I., Holle, H., Rein, R., \& Lausberg, H. (2015). Brain oxygenation patterns during the execution of tool use demonstration, tool use pantomime, and body-part-as-object tool use. International Journal of Psychophysiology, 96, 1-7. https://doi. org/10.1016/j.ijpsycho.2015.03.001

Helon, H., \& Kroliczak, G. (2014). The effects of visual half-field priming on the categorization of familiar intransitive gestures, tool use pantomimes, and meaningless hand movements. Frontiers in Psychology, 5, 454. https://doi.org/10.3389/fpsyg.2014.00454

Hickok, G., \& Poeppel, D. (2000). Towards a functional neuroanatomy of speech perception. Trends in Cognitive Science, 4, 131-138. https://doi.org/10.1016/ S1364-6613(00)01463-7

Hickok, G., \& Poeppel, D. (2007). The cortical organization of speech processing. Nature Reviews Neuroscience, 8, 393-402. https://doi.org/10.1038/nrn2113

Hickok, G., \& Poeppel, D. (2015). Neural basis of speech perception. Handbook of Clinical Neurology, 129, 149-160. https://doi.org/10.1016/B978-0444-62630-1.00008-1

Huang, K., Itoh, K., Kwee, I. L., \& Nakada, T. (2012). Neural strategies for reading Japanese and Chinese sentences: a cross-linguistic fMRI study of character-decoding and morphosyntax. Neuropsychologia, 50, 2598-2604. https://doi.org/10.1016/j. neuropsychologia.2012.07.011

Hugdahl, K. (2012). Auditory laterality: Dichotic listening and fMRI studies. Advances in Clinical Neuroscience and Rehabilitation, 11, 23-24.

Hull, R., \& Vaid, J. (2007). Bilingual language lateralization: a meta-analytic tale of two hemispheres. Neuropsychologia, 45, 1987-2008. https://doi.org/ 10.1016/j.neuropsychologia.2007.03.002

Hund-Georgiadis, M., Lex, U., Friederici, A. D., \& von Cramon, D. Y. (2002). Non-invasive regime for lan- guage lateralization in right- and left-handers by means of functional MRI and dichotic listening. Experimental Brain Research, 145, 166-176. https:// doi.org/10.1007/s00221-002-1090-0

Hunter, Z. R., \& Brysbaert, M. (2008). Visual halffield experiments are a good measure of cerebral language dominance if used properly: Evidence from fMRI. Neuropsychologia, 46, 316-325. https:// doi.org/10.1016/j.neuropsychologia.2007.07.007

Johnson-Frey, S. H. (2004). The neural bases of complex tool use in humans. Trends in Cognitive Science, 8, 71-78. https://doi.org/10.1016/j.tics.2003.12.002

Johnson-Frey, S. H., Newman-Norlund, R., \& Grafton, S. T. (2005). A distributed left hemisphere network active during planning of everyday tool use skills. Cerebral Cortex, 15, 681-695. https://doi. org/10.1093/cercor/bhh 169

Joliot, M., Tzourio-Mazoyer, N., \& Mazoyer, B. (2016). Intra-hemispheric intrinsic connectivity asymmetry and its relationships with handedness and language lateralization. Neuropsychologia, 93, 437-447. https://doi.org/10.1016/j.neuropsychologia.2016.03.013

Kim, S. Y., Qi, T., Feng, X., Ding, G., Liu, L., \& Cao, F. (2016). How does language distance between L1 and L2 affect the L2 brain network? An fMRI study of KoreanChinese-English trilinguals. Neurolmage, 129, 25-39. https://doi.org/10.1016/j.neuroimage.2015.11.068

Kimura, D. (2011). From ear to brain. Brain and Cognition, 76, 214-217. https://doi.org/10.1016/j.bandc. 2010.11.009

Klichowski, M., \& Kroliczak, G. (2017). Numbers and functional lateralization: a visual half-field and dichotic listening study in proficient bilinguals. Neuropsychologia, 100, 93-109. https://doi.org/10.1016/j. neuropsychologia.2017.04.019

Knecht, S., Drager, B., Deppe, M., Bobe, L., Lohmann, H., Floel, A., Ringelstein, E. B., \& Henningsen, H. (2000). Handedness and hemispheric language dominance in healthy humans. Brain, 123, 2512-2518. https:// doi.org/10.1093/brain/123.12.2512

Kohler, E., Keysers, C., Umilta, M. A., Fogassi, L., Gallese, V., \& Rizzolatti, G. (2002). Hearing sounds, understanding actions: Action representation in mirror neurons. Science, 297, 846-848. https://doi. org/10.1126/science. 1070311

Krefta, M., Michalowski, B., Kowalczyk, J., \& Kroliczak, G. (2015). Co-lateralized bilingual mechanisms for reading in single and dual language contexts: Evidence from visual half-field processing of action words in proficient bilinguals. Frontiers in Psychology, 6, 1159. https://doi.org/10.3389/ fpsyg.2015.01159

Kroliczak, G., Piper, B. J., \& Frey, S. H. (2011). Atypical lateralization of language predicts cerebral asymmetries in parietal gesture representations. Neuropsychologia, 49, 1698-1702. https://doi.org/10.1016/j. neuropsychologia.2011.02.044
Tool-sound processing in a bilingual brain 
Michal Klichowski, Agnieszka Nowik, Gregory Kroliczak, James W. Lewis
Kroliczak, G., Piper, B. J., \& Frey, S. H. (2016). Specialization of the left supramarginal gyrus for hand-independent praxis representation is not related to hand dominance. Neuropsychologia, 93, 501-512. https:// doi.org/10.1016/j.neuropsychologia.2016.03.023

Kroliczak, G., Westwood, D. A., \& Goodale, M. A. (2006). Differential effects of advance semantic cues on grasping, naming, and manual estimation. Experimental Brain Research, 175, 139-152. https:// doi.org/10.1007/s00221-006-0524-5

Kuhl, P. K., Stevenson, J., Corrigan, N. M., van den Bosch, J. J. F., Can, D. D., \& Richards, T. (2016). Neuroimaging of the bilingual brain: Structural brain correlates of listening and speaking in a second language. Brain and Language, 162, 1-9. https://doi. org/10.1016/j.bandl.2016.07.004

Lane, C., Kanjlia, S., Richardson, H., Fulton, A., Omaki, A., \& Bedny, M. (2017). Reduced left lateralization of language in congenitally blind individuals. Journal of Cognitive Neuroscience, 29, 65-78. https://doi.org/10.1162/jocn_a_01045

Lewis, J.W. (2006). Cortical networks related to human use of tools. Neuroscientist, 12, 211-231. https:/doi. org/10.1177/1073858406288327

Lewis, J. W., Brefczynski, J. A., Phinney, R. E., Janik, J. J., \& DeYoe, E. A. (2005). Distinct cortical pathways for processing tool versus animal sounds. Journal of Neuroscience, 25, 5148-5158. https://doi. org/10.1523/JNEUROSCI.0419-05.2005

Lewis, J. W., Phinney, R. E., Brefczynski-Lewis, J. A., \& DeYoe, E. A. (2006). Lefties get it „right” when hearing tool sounds. Journal of Cognitive Neuroscience, 18, 1314-1330. https://doi.org/10.1162/jocn. 2006.18.8.1314

Lewis, J. W., Silberman, M. J., Donai, J. J., Frum, C.A., \& Brefczynski-Lewis, J. A. (2018). Hearing and orally mimicking different acoustic-semantic categories of natural sound engage distinct left hemisphere cortical regions. Brain and Language, 183, 64-78. https://doi.org/10.1016/j.bandl.2018.05.002

Liegeois, F., Connelly, A., Baldeweg, T., \& VarghaKhadem, F. (2008). Speaking with a single cerebral hemisphere: fMRI language organization after hemispherectomy in childhood. Brain and Language, 106, 195-203. https://doi.org/10.1016/j. bandl.2008.01.010

Liu, H., \& Cao, F. (2016). L1 and L2 processing in the bilingual brain: a meta-analysis of neuroimaging studies. Brain and Language, 159, 60-73. https:// doi.org/10.1016/j.bandl.2016.05.013

McNair, N. A., \& Harris, I. M. (2012). Disentangling the contributions of grasp and action representations in the recognition of manipulable objects. Experimental Brain Research, 220, 71-77. https:// doi.org/10.1007/s00221-012-3116-6

Michel, G. F. (2017). How might the relation of the development of hand preferences to the development of cognitive functions be examined during infancy: a sketch? Frontiers in Neuroscience, 11, 739. https://doi.org/10.3389/fnins.2017.00739

Nakada, T., Fujii, Y., \& Kwee, I. L. (2001). Brain strategies for reading in the second language are determined by the first language. Neuroscience Research, 40, 351358. https://doi.org/10.1016/S0168-0102(01)00247-4

Nelson, J. R., Liu, Y., Fiez, J., \& Perfetti, C. A. (2009). Assimilation and accommodation patterns in ventral occipitotemporal cortex in learning a second writing system. Human Brain Mapping, 30, 810820. https://doi.org/10.1002/hbm.20551

Oertel, D., Cao, X. J., Ison, J. R., \& Allen, P. D. (2017). Cellular computations underlying detection of gaps in sounds and lateralizing sound sources. Trends in Neurosciences, 40, 613-624. https://doi. org/10.1016/j.tins.2017.08.001

Oltedal, L., \& Hugdahl, K. (2017). Opposite brain laterality in analogous auditory and visual tests. Laterality, 22, 690-702. https://doi.org/10.1080/135 7650X.2016.1269335

Park, H. R., Badzakova-Trajkov, G., \& Waldie, K. E. (2012). Language lateralisation in late proficient bilinguals: a lexical decision fMRI study. Neuropsychologia, 50, 688-695. https://doi.org/10.1016/j. neuropsychologia.2012.01.005

Peng, G., \& Wang, W. S. (2011). Hemisphere lateralization is influenced by bilingual status and composition of words. Neuropsychologia, 49, 19811986. https://doi.org/10.1016/j.neuropsychologia. 2011.03.027

Poeppel, D. (2001). Pure word deafness and the bilateral processing of the speech code. Cognitive Science, 25, 679-693. https://doi.org/10.1207/ s15516709cog2505_3

Przybylski, L., \& Kroliczak, G. (2017). Planning functional grasps of simple tools invokes the handindependent praxis representation network: an fMRI study. Journal of the International Neuropsychological Society, 23, 108-120. https://doi. org/10.1017/S1355617716001120

Pulvermuller, F., \& Fadiga, L. (2010). Active perception: Sensorimotor circuits as a cortical basis for language. Nature Reviews Neuroscience, 11, 351360. https://doi.org/10.1038/nrn2811

Reifegerste, J., Elin, K., \& Clahsen, H. (2019). Persistent differences between native speakers and late bilinguals: Evidence from inflectional and derivational processing in older speakers. Bilingualism: Language and Cognition, 22, 425-440. https://doi. org/10.1017/S1366728918000615P

Rizzolatti, G., Fadiga, L., Matelli, M., Bettinardi, V., Paulesu, E., Perani, D., \& Fazio, F. (1996). Localization of grasp representations in humans by PET: 1 . Observation versus execution. Experimental Brain Research, 111, 246-252. https://doi.org/10.1007/ BF00227301

Schneider, D. M., Sundararajan, J., \& Mooney, R. (2018). A cortical filter that learns to suppress the 
acoustic consequences of movement. Nature, 561, 391-395. https://doi.org/10.1038/s41586-018-0520-5

Skoe, E., Burakiewicz, E., Figueiredo, M., \& Hardin, M. (2017). Basic neural processing of sound in adults is influenced by bilingual experience. $\mathrm{Neu}$ roscience, 349, 278-290. https://doi.org/10.1016/j. neuroscience.2017.02.049

Somers, M., Aukes, M. F., Ophoff, R. A., Boks, M. P., Fleer, W., de Visser, K. C., Kahn, R. S., \& Sommer, I. E. (2015). On the relationship between degree of hand-preference and degree of language lateralization. Brain and Language, 144, 10-15. https://doi.org/10.1016/j.bandl.2015.03.006

Stein, M., Winkler, C., Kaiser, A., \& Dierks, T. (2014). Structural brain changes related to bilingualism: Does immersion make a difference? Frontiers in Psychology, 5, 1116. https://doi.org/10.3389/fpsyg. 2014.01116

Styrkowiec, P. P., Nowik, A. M., \& Kroliczak, G. (2019). The neural underpinnings of haptically guided functional grasping of tools: an fMRI study. Neurolmage, 194, 149-162. https://doi.org/10.1016/j. neuroimage.2019.03.043

Tan, L. H., Spinks, J. A., Feng, C. M., Siok, W. T., Perfetti, C. A., Xiong, J., Fox, P. T., \& Gao, J. H. (2003). Neural systems of second language reading are shaped by native language. Human Brain Mapping, 18, 158-166. https://doi.org/10.1002/hbm.10089

Tivarus, M. E., Starling, S. J., Newport, E. L., \& Langfitt, J. T. (2012). Homotopic language reorganization in the right hemisphere after early left hemisphere injury. Brain and Language, 123, 1-10. https://doi.org/10.1016/j.bandl.2012.06.006

Van der Haegen, L., Cai, Q., Seurinck, R., \& Brysbaert, M. (2011). Further fMRI validation of the visual half field technique as an indicator of language laterality: a large-group analysis. Neuropsy chologia, 49, 2879-2888. https://doi.org/10.1016/j. neuropsychologia.2011.06.014

van der Noort, M., Struys, E., Kim, K., Bosch, P., Mondt, K., van Kralingen, R., Lee, M., \& van de Craen, P. (2014). Multilingual processing in the brain. International Journal of Multilingualism, 11, 182-201. https://doi.org/10.1080/14790718.2013.791298

Veale, J. F. (2014). Edinburgh Handedness Inventory - Short Form: a revised version based on confirmatory factor analysis. Laterality, 19, 164-177. https://doi.org/10.1080/1357650X.2013.783045

Verma, A., \& Brysbaert, M. (2011). A right visual field advantage for tool-recognition in the visual halffield paradigm. Neuropsychologia, 49, 2342-2348. https://doi.org/10.1016/j.neuropsychologia.2011. 04.007

Vingerhoets, G., Acke, F., Alderweireldt, A. S., Nys, J., Vandemaele, P., \& Achten, E. (2012). Cerebral lateralization of praxis in right- and left-handedness: Same pattern, different strength. Human Brain Mapping, 33, 763-777. https://doi.org/10.1002/hbm.21247
Vingerhoets, G., Alderweireldt, A. S., Vandemaele, P., Cai, Q., Van der Haegen, L., Brysbaert, M., \& Achten, E. (2013). Praxis and language are linked: Evidence from co-lateralization in individuals with atypical language dominance. Cortex, 49, 172-183. https://doi.org/10.1016/j.cortex.2011.11.003

Wild, C. J., Linke, A. C., Zubiaurre-Elorza, L., Herzmann, C., Duffy, H., Han, V. K., Lee, D. S. C., \& Cusack, R. (2017). Adult-like processing of naturalistic sounds in auditory cortex by 3- and 9-month old infants. Neurolmage, 157, 623-634. https://doi. org/10.1016/j.neuroimage.2017.06.038

Willemin, J., Hausmann, M., Brysbaert, M., Dael, N., Chmetz, F., Fioravera, A., Gieruc, K., \& Mohr, C. (2016). Stability of right visual field advantage in an international lateralized lexical decision task irrespective of participants' sex, handedness or bilingualism. Laterality, 21, 502-524. https://doi.or g/10.1080/1357650X.2015.1130716

Wu, Y. J., \& Thierry, G. (2017). Brain potentials predict language selection before speech onset in bilinguals. Brain and Language, 171, 23-30. https:// doi.org/10.1016/j.bandl.2017.04.002
Tool-sound processing in a bilingual brain 


\section{Appendix A: Stimuli used in VHF tests}

Polish action words: celować; czyścić; fotografować; kroić; malować; masować; mieszać; odkurzać; pakować; pisać; podkreślać; podlewać; prasować; rysować; strzelać; szczotkować; szlifować; wycinać; zmywać; zamykać.

English action words: aiming; brushing; cleaning; close; cutting; drawing; grinding; highlight; ironing; massaging; mixing; packaging; painting; photograph; shooting; slicing; vacuuming; washing; watering; writing.

\section{Appendix B: Stimuli used in DL tests}

Michal Klichowski, Agnieszka Nowik, Gregory Kroliczak, James W. Lewis
Polish action words: celować; czyścić; fotografować; kroić; malować; masować; mieszać; odkurzać; pakować; pisać; podkreślać; podlewać; prasować; rysować; strzelać; szczotkować; szlifować; wycinać; zmywać; zamykać.

English action words: aiming; brushing; cleaning; close; cutting; drawing; grinding; highlight; ironing; massaging; mixing; packaging; painting; photograph; shooting; slicing; vacuuming; washing; watering; writing.

Polish names of tool sounds: czyścić; grabić; kleić; kopać; kroić; malować; ostrzyć; piłować; pisać; pompować; przepychać; rabać; rysować; spitowywać; sptukiwać; stemplować; szlifować; wbijać; wycinać; zszywać.

English names of tool sounds: chop; clean; cut; dig; draw; file off; grind; hammer; paint; pump; rake; rinse; saw; sharpen; slice; stamp; staple; tape; unclog; write. 